\title{
Effect of Summer Arctic Sea Ice on the Reverse August Precipitation Anomaly in Eastern China between 1998 and 2016
}

\author{
HAIBO SHEN \\ Collaborative Innovation Center on Forecast and Evaluation of Meteorological Disasters/Key Laboratory of \\ Meteorological Disaster, Ministry of Education, Nanjing University of Information \\ Science and Technology, Nanjing, China \\ SHENGPING HE \\ Geophysical Institute, University of Bergen and Bjerknes Centre for Climate Research, Bergen, Norway, and \\ Collaborative Innovation Center on Forecast and Evaluation of Meteorological Disasters/Key \\ Laboratory of Meteorological Disaster, Ministry of Education, Nanjing University of \\ Information Science and Technology, Nanjing, China

\section{HUIJUN WANG} \\ Collaborative Innovation Center on Forecast and Evaluation of Meteorological Disasters/Key Laboratory of \\ Meteorological Disaster, Ministry of Education, Nanjing University of Information Science and \\ Technology, Nanjing, and Climate Change Research Center, and Nansen-Zhu International \\ Research Center, Institute of Atmospheric Physics, and Climate Change \\ Research Center, Chinese Academy of Sciences, Beijing, China
}

(Manuscript received 15 September 2017, in final form 24 January 2019)

\begin{abstract}
The 1997/98 and 2015/16 El Niño episodes are regarded as two super-El Niño events and have exerted profound influence on eastern China summer rainfall, as expected. However, on the subseasonal time scale, summer rainfall in these two years shows dramatic diversity, although the characteristics of the two super-El Niños are similar. This study reveals that the rainfall increased (decreased) over central China $\left(\sim 30^{\circ}-35^{\circ} \mathrm{N}\right)$ and decreased (increased) over southeastern China (south of $\sim 25^{\circ} \mathrm{N}$ ) in August 1998 (2016), exhibiting a dipole anomaly pattern over eastern China. Observational analyses indicate that, associated with negative interannual variability of the sea ice area (SIA) over the Barents-Kara Seas (BKS) in July and August, August rainfall shows significantly negative (positive) anomalies over central (southeastern) China. Further analyses reveal that negative SIA anomalies in the BKS induce significantly anomalous upper-level divergence over the polar region, accompanied with anomalous upper-level convergence over the Caspian Sea. The advection of vorticity by these anomalous divergent and convergent flows indicates notable Rossby wave sources near the Caspian Sea, yielding a Rossby wave train propagating eastward to East Asia that causes positive barotropic and baroclinic energy convection near the exit region of the Asian jet stream. The accumulation of perturbation energy in East Asia stimulates the formation of the Pacific-Japan teleconnection, which is favorable for the dipole rainfall anomaly pattern over eastern China. Thus, the positive and negative SIA anomaly over the BKS in 1998 and 2016 may contribute to the reverse August precipitation anomaly in eastern China.
\end{abstract}

\section{Introduction}

The dominant spatial distribution of summer rainfall anomalies over eastern China (which represents central eastern China and southeastern China hereinafter, that is, $20^{\circ}-35^{\circ} \mathrm{N}, 105^{\circ}-120^{\circ} \mathrm{E}$ ) often exhibits a zonally

Corresponding author: Haibo Shen, shb1992@126.com elongated and meridionally banded anomaly structure, indicating a meridionally tripole pattern or a meridionally dipole pattern (Ding et al. 2008; Han and Zhang 2009; Liu et al. 2011; Jin et al. 2016). He et al. (2017) suggested that the leading mode of summer rainfall shows differences in separate periods, which is characterized by a meridional tripole structure during 1979-93 and a meridional dipole structure during 1994-2014. 
The interannual variability of the meridional rainfall structure is often concurrent with floods and droughts in different areas in eastern China, exerting dramatic influence on life security and economic development in local and surrounding regions.

The mechanism of the interannual variability of eastern China summer rainfall is very complex and widely investigated. The tropical ocean surface temperature is recognized as a notable external forcing on the variability of the summer rainfall in eastern China. Although the positive sea surface temperature (SST) anomaly in the tropical eastern Pacific dissipates in summer after a mature El Niño, a significant El Niño-related effect still exists. Many researchers suggested that a prominent positive precipitation anomaly occurs near the Yangtze River (approximately $28^{\circ}-33^{\circ} \mathrm{N}$ ) during the summers associated with ENSO decay phase (Huang and Wu 1989; Jin and Tao 1999; Huang et al. 2004; Hu and Huang 2010; Zeng et al. 2011). Wang et al. (2000) attributed such a relationship to the lower-tropospheric anticyclone over the Philippine Sea and illustrated that this anticyclone persists from the peak El Niño to the ensuing summer, strengthening the western Pacific subtropical ridge in summer, which then causes abundant rainfall in the lower reach of the Yangtze River valley. Furthermore, El Niño Modoki can also cause the anomalous western North Pacific (WNP) anticyclone and anomalous moisture transport to East Asia, but the features show differences from that associated with the traditional El Niño (Feng et al. 2011; Li et al. 2014). In addition, some other studies documented that the tropical Indian Ocean (TIO) SST acts like a capacitor, anchoring atmospheric anomalies over the Indo-western Pacific Ocean under the influence of a lingering El Niño (Yang et al. 2007; Xie et al. 2009; Wu et al. 2018). They suggested that the positive TIO SST anomaly (SSTA) causes increased tropospheric temperature, emanating a baroclinic Kelvin wave into the Pacific Ocean. The Kelvin wave induces northeasterly wind anomalies, resulting in divergence in the subtropics and an anomalous anticyclone over the tropical western Pacific (Xie et al. 2009). Based on the wintertime tropical SSTA signals, Li et al. (2016) improves the seasonal prediction of Huai River valley heavy rainfall by implementing a three-cluster normal mixture model.

The East Asia-Pacific/Pacific-Japan pattern (EAP/PJ pattern) is another frequently cited pathway that exerts notable influence on the summer precipitation in eastern China, which often occurs in the summers following a mature El Niño (Hsu and Lin 2007; Huang et al. 2012; Chen and Zhou 2014). With regard to the formation of the PJ pattern, primary theories suggested that anomalous SST over the Philippine Sea is the major forcing for the PJ pattern (Nitta 1987; Nitta and Hu 1996). Meanwhile, enhanced (suppressed) convective heating over the Philippine Sea can also excite a positive (negative) PJ pattern (Kosaka and Nakamura 2006). The positive phase of the PJ pattern produces a meridional wave train poleward along the East Asian coast, with an anomalous cyclonic circulation over the Indo-China Peninsula to the Philippine Sea and the Okhotsk Sea, concurrent with an anomalous anticyclone over North China to Japan at the 500-hPa level (Nitta 1987; Kosaka and Nakamura 2006). This structure of atmospheric circulation results in northward movement of the WNP subtropical high and less moisture transport to the Yangtze-Huai River valley, which hence modulates the summer rainfall in eastern China.

Although the modulation of El Niño on summer rainfall in eastern China has been widely recognized, the variances of rainfall have not been well explained in some El Niño cases (Ding et al. 2008; Wu et al. 2009; Wu et al. 2018). Wang (2002) also noted that the relationship between the ENSO and the East Asian summer monsoon (EASM), which dominants the summer rainfall variability over eastern China, is unstable. The unstable EASM-ENSO relationship implies that there are some other potential factors impacting the variability of summer rainfall over eastern China.

Previous studies revealed the influence of Arctic sea ice on atmospheric teleconnections in the Northern Hemisphere during boreal winter (Chen et al. 2009; Liu et al. 2012; Tang et al. 2013). In addition, the summer precipitation anomalies in Europe, the Mediterranean, and East Asia are also suggested to be correlated with the Arctic sea ice cover anomaly (Wang and Zhang 2010; Screen 2013; Vihma 2014; Lin and Li 2018). Based on the observed data and modeling experiments, Zhao et al. (2004) suggested that decreasing spring sea ice extent over the Bering Sea and the Sea of Okhotsk causes increased summer rainfall in southeastern China by generating an anomalous high in East Asia and then hence anchoring the mei-yu front in southeastern China. Wu et al. (2009) employed singular value decomposition (SVD) to investigate the relationship between the spring Arctic sea ice concentration (SIC) and Chinese summer rainfall. Results showed that decreased (increased) spring SIC in the Arctic Ocean and the Greenland Sea corresponds to increased (decreased) summer rainfall in northeast and central China and decreased (increased) rainfall in southeastern China. They suggested that the summer Arctic dipole anomaly is the bridge connecting spring Arctic sea ice and summer precipitation in China. Meanwhile, a recent research proposed that the spring Arctic sea ice influences the East Asian summer rainfall via the persistent SSTA in the North Pacific (Guo et al. 2014). 
Although many previous studies have demonstrated the potential effect of the external factors on the rainfall anomalies over China, most researches mainly focused on summer-mean rainfall. Some recent studies have noted the subseasonal variability of rainfall in eastern China during summer. As suggested by Wang et al. (2009), because of remarkable differences in mean states between May-June (MJ) and July-August (JA), separately predicting the precipitation anomalies for MJ and JA may help improve seasonal predictions of summer rainfall over East Asia. The predictability of ENSO-related MJ and JA rainfall modes has been tested by 12 atmospheric general circulation models driven by SST ( $\mathrm{Li}$ and Zhou 2011). Other research used extended SVD to explore the relationship between the winter SSTA in the tropical Pacific and the intraseasonal variation of China's rainfall in the following summer. It is revealed that the rainfall anomaly pattern shows significant distinctions between June, July, and August following the winter El Niño events (Huang and Huang 2010). Wang and He (2015) also found that the rainfall anomalies in East Asia were reversed between June and August in the summer of 2014. Moreover, some recent model simulations suggested that the rainfall variability in June, July, and August over China is related to the SSTA of different regions (Xu et al. 2017b) and the SSTA in the tropical Pacific is not the unique impact factor on the summer rainfall anomaly over China (Xu et al. 2017a).

Observations indicate that the 1997/98 and 2015/16 El Niño episodes are the two strongest events based on various detection indices since the data record began (Shao and Zhou 2016). As suggested by previous studies (Lau and Weng 2001; Zhai et al. 2016), the summers of 1998 and 2016 saw more abundant precipitation over central China (Figs. 1e,f). Although the summer-mean rainfall anomalies in 1998 and 2016 are similarly enhanced in central China, the monthly rainfall anomalies over eastern China are quite different (shown in section 3). Wang and $\mathrm{He}$ (2015) have suggested the potential role of the midlatitude wave train in linking the Arctic sea ice to the eastern China summer rainfall on the subseasonal time scale; however, detailed physical mechanisms have not been documented. The studies cited above motivate us to examine the potential impact of sea ice over the BarentsKara Seas on the diversity of subseasonal precipitation anomalies over eastern China in summers of 1998 and 2016.

\section{Data and methods}

The monthly precipitation observation data adopted in this study include the National Oceanic and Atmospheric Administration (NOAA) Precipitation Reconstruction over Land $(\mathrm{PREC} / \mathrm{L})$ with a resolution of $1^{\circ} \times 1^{\circ}$
(Chen et al. 2002) and a 160-station dataset from the China Meteorological Administration. Monthly SST and sea ice concentration are provided by the Met Office Hadley Centre (Rayner et al. 2003), with a resolution of $1^{\circ} \times 1^{\circ}$. Atmospheric data are derived from the National Centers for Environmental Prediction-National Center for Atmospheric Research (NCEP-NCAR) reanalysis (Kalnay et al. 1996) with a horizontal resolution of $2.5^{\circ} \times$ $2.5^{\circ}$. All the datasets and analyses cover the period of 1979-2016. The anomaly in this study refers to the departures relative to the climatology of 1980-2010.

The sea ice area used in the paper is area-integrated from the Hadley Center sea ice concentration. Based on Huang (2004), the PJ pattern index (PJI) employed in the study is defined as

$$
\begin{aligned}
\mathrm{PJI}= & -0.25 Z_{S}^{\prime}\left(60^{\circ} \mathrm{N}, 125^{\circ} \mathrm{E}\right)+0.5 Z_{S}^{\prime}\left(40^{\circ} \mathrm{N}, 125^{\circ} \mathrm{E}\right) \\
& -0.25 Z_{S}^{\prime}\left(20^{\circ} \mathrm{N}, 125^{\circ} \mathrm{E}\right) .
\end{aligned}
$$

Here, $Z_{S}^{\prime}=Z^{\prime} \sin 45^{\circ} / \sin \varphi$, which indicates the standardized 500-hPa height anomaly at a grid point with latitude $\varphi ; Z^{\prime}=Z-\bar{Z}$ is the $500-\mathrm{hPa}$ height anomaly at the specified grid point; $Z$ is the $500-\mathrm{hPa}$ height and $\bar{Z}$ is the long-term mean of it. To illustrate the wavelike activity, the 3D wave activity flux is applied in the study (Takaya and Nakamura 2001). The barotropic energy conversion (CK) and baroclinic energy conversion (CP) are calculated based on the formula below (Hoskins et al. 1983; Simmons et al. 1983):

$$
\begin{aligned}
\mathrm{CK} & =\frac{v^{\prime 2}-u^{\prime 2}}{2}\left(\frac{\partial \bar{u}}{\partial x}-\frac{\partial \bar{v}}{\partial y}\right)-u^{\prime} v^{\prime}\left(\frac{\partial \bar{u}}{\partial y}+\frac{\partial \bar{v}}{\partial x}\right), \\
\mathrm{CP} & =-\left(\frac{f}{\sigma} v^{\prime} T^{\prime} \frac{\partial \bar{u}}{\partial p}+\frac{f}{\sigma} u^{\prime} T^{\prime} \frac{\partial \bar{v}}{\partial p}\right), \quad \text { and } \\
\sigma & =\left(R \bar{T} / C_{p} p\right)-d \bar{T} / d p .
\end{aligned}
$$

Here, $u$ and $v$ are the wind vectors, $T$ is the temperature, $f$ is the Coriolis parameter, $R$ is the gas constant, and $C_{p}$ is the specific heat at constant pressure. Overbars and primes denote basic-state quantities and perturbations.

Model simulations are also employed to provide more evidence for the dynamic diagnostic analysis. The model used in the study is the version 4 of the Community Atmosphere Model (CAM4), with a $1.9^{\circ} \times 2.5^{\circ}$ finitevolume grid, and with 26 hybrid sigma pressure levels.

\section{Reverse precipitation anomaly in August between 1998 and 2016}

In 2015, remarkable El Niño features appeared after spring when the westerly wind anomalies at the lower 
(a) SSTA, DJF, 1997/1998

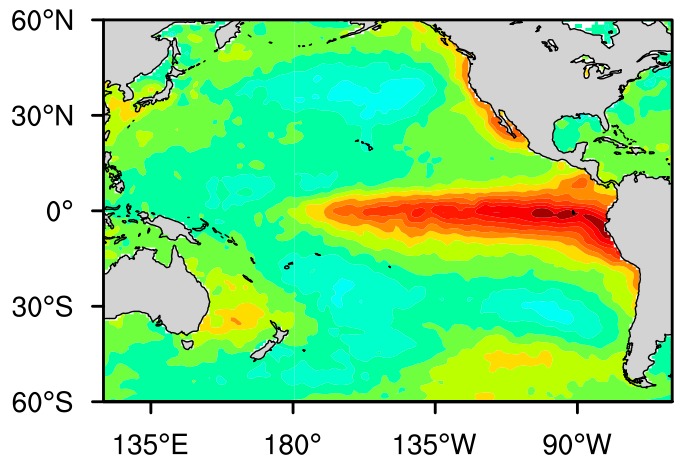

(c) SSTA, JJA, 1998

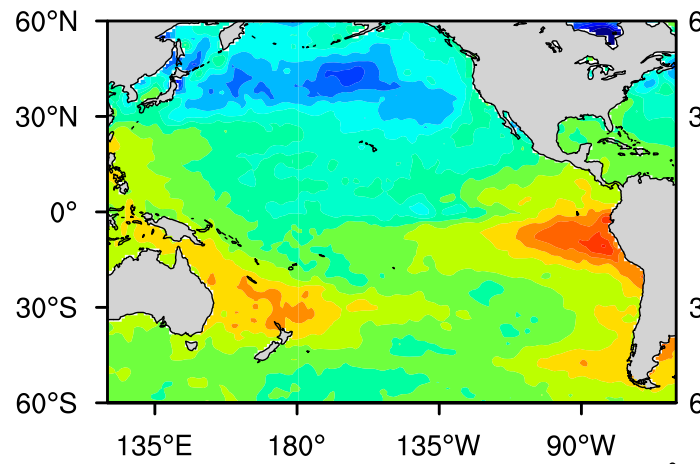

(b) SSTA, DJF, 2015/2016

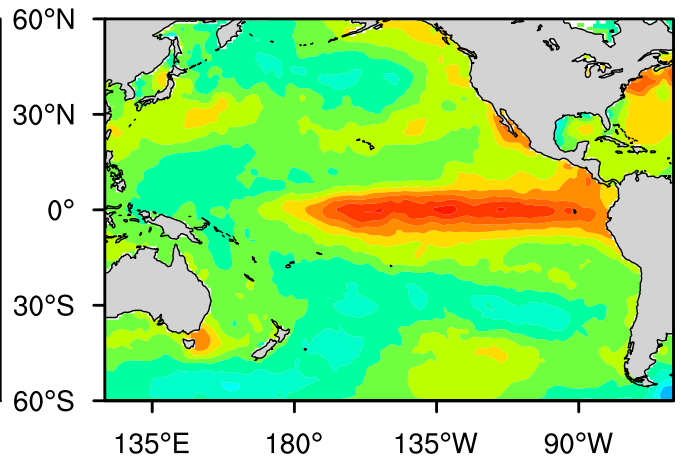

(d) SSTA, JJA, 2016

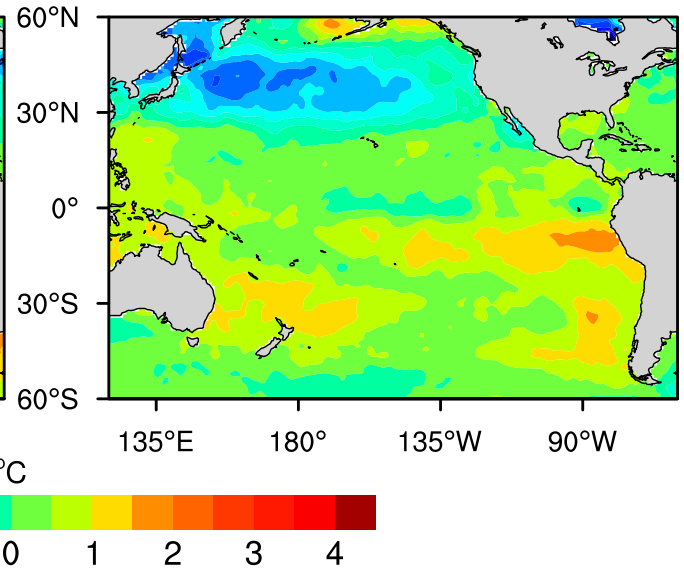

(e)precip anomaly, JJA, 1998

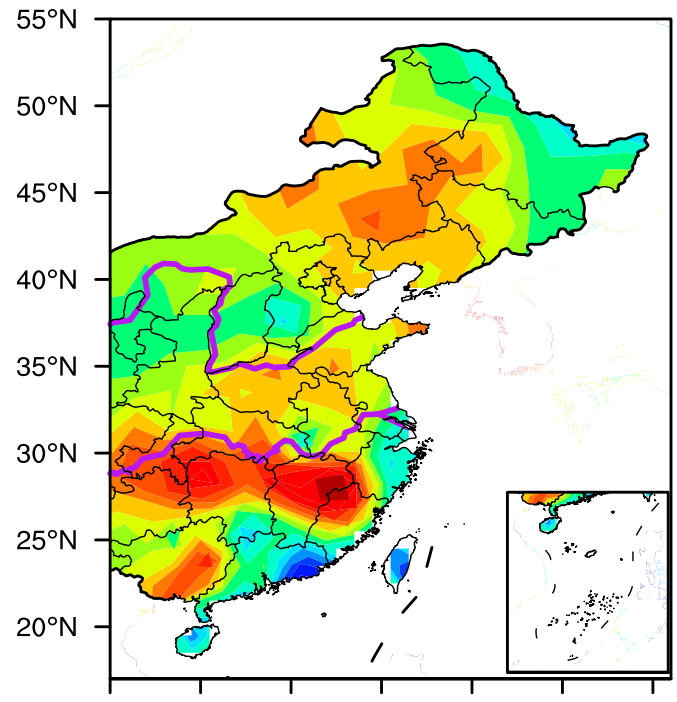

$105^{\circ} \mathrm{E} 110^{\circ} \mathrm{E} 115^{\circ} \mathrm{E} 120^{\circ} \mathrm{E} 125^{\circ} \mathrm{E} 130^{\circ} \mathrm{E} 135^{\circ} \mathrm{E}$

(f)precip anomaly, JJA, 2016

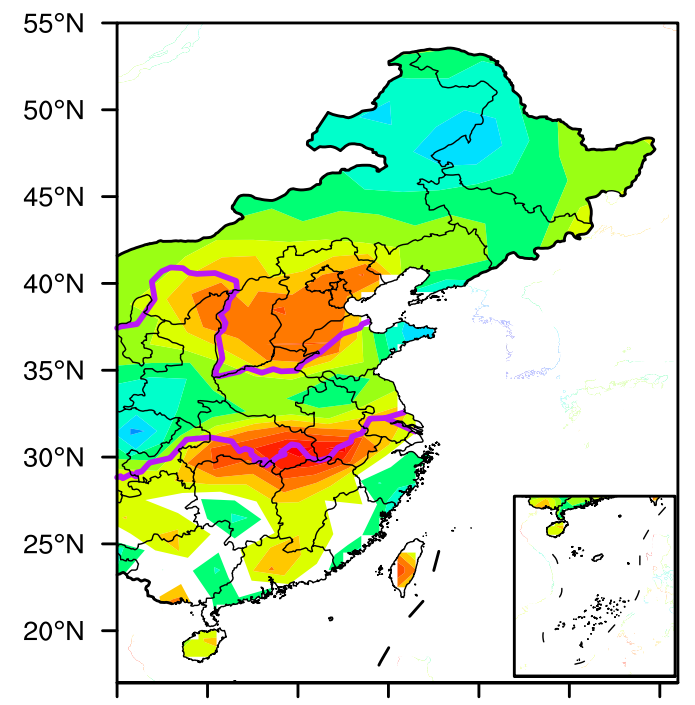

$105^{\circ} \mathrm{E} 110^{\circ} \mathrm{E} 115^{\circ} \mathrm{E} 120^{\circ} \mathrm{E} 125^{\circ} \mathrm{E} 130^{\circ} \mathrm{E} 135^{\circ} \mathrm{E}$ $\mathrm{mm} / \mathrm{day}$

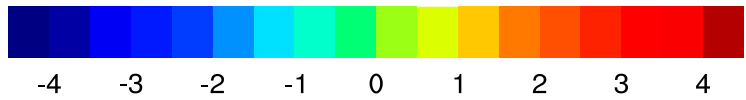

FIG. 1. Distributions of SSTA $\left({ }^{\circ} \mathrm{C}\right.$ ) in (a) DJF 1997/98, (b) DJF 2015/16, (c) JJA 1998, and (d) JJA 2016. (e), (f) Precipitation anomalies ( $\mathrm{mm} \mathrm{day}^{-1}$ ) in China east of $105^{\circ} \mathrm{E}$ during JJA in 1998 and 2016, respectively. 
troposphere became prominent over the equatorial Pacific and large-scale positive SSTA covered the central-eastern Pacific. Thereafter, winter 2015 saw a well-developed El Niño that is regarded as a superstrong El Niño episode similar to the 1997/98 El Niño event (Zhai et al. 2016). According to the winter-mean [December-February (DJF)] SSTA in the central-eastern tropical Pacific (Figs. 1a,b) in 1997/98 and 2015/16, the SSTA modes of the two El Niño events are similar. Additionally, the Niño-3.4 indices of winters 1997/98 and 2015/16 are 2.2 and 2.5, respectively, which are the two highest winter values since 1950 (http:/www.cpc.ncep.noaa.gov/products/ analysis_monitoring/ensostuff/ensoyears.shtml). Therefore, from the distribution of the SSTA over the eastern tropical Pacific and the Niño-3.4 indices during the mature phase, the intensities of the two super-El Niño events are extremely strong and close. Zhai et al. (2016) also investigated the monthly SSTA indices for other Niño regions defined by $\mathrm{Li}$ and Zhai (2000) and the Southern Oscillation index in 1997/98 and 2015/16, suggesting that the conditions of the two El Niño events are analogous. Furthermore, following the mature El Niño during winter, the two cases manifested similar SST conditions over the tropical Pacific in the El Niño decay phase (Figs. 1c,d). The summer-mean [June-August (JJA)] SSTA was positive (negative) in the south (north) of $30^{\circ} \mathrm{N}$ over the North Pacific in the two years and the positive SSTA in 2016 was slightly stronger than that in 1998 (Fig. 1c vs Fig. 1d). Overall, the 1997/98 and 2015/16 events are the top two superstrong El Niño episodes since 1950. According to the conclusions in previous studies (Wang et al. 2000; Huang et al. 2004), the SSTA over the tropical Pacific associated with the 2015/16 El Niño should have led to similar anomalous summer precipitation pattern in eastern China that occurred in the summer of 1998.

Actually, the total rainfall in central China during the summers of 1998 and 2016 did remarkably increase (Figs. 1e,f). Considering the potential differences of subseasonal variability of summer precipitation over China (Wang et al. 2009; Wang and He 2015; Xu et al. 2017 b), we further examine the monthly precipitation anomalies and SSTA in June, July, and August during 1998 and 2016. In June and July, positive precipitation anomalies appeared in central China during both 1998 and 2016 (Fig. 2), which indicates the influence of the super-El Niño. However, the August rainfall in eastern China associated with the two El Niño events showed apparent diversity (Fig. 3). Figures 3a and 3b show that the precipitation anomalies over eastern China in August 1998 and 2016, respectively. In August 1998, a positive precipitation anomaly appeared in central China, while a negative anomaly emerged in southeastern China. Such a "south drought-north flood" pattern is suggested to be related to the El Niño influence (Wang et al. 2000; Huang et al. 2004). Surprisingly, reverse conditions occurred in August 2016, with positive rainfall anomaly in southeastern China and negative anomaly in central China, which is unexpected in the super-El Niño decay phase. Meanwhile, observations from the 160-station dataset also display a reverse precipitation anomaly pattern in August between 1998 and 2016 (Figs. 3c,d).

Why is the August precipitation anomaly over eastern China inverse under two similar super-El Niño conditions? Addressing this question is very important for further understanding the interannual variability of eastern China summer rainfall. The distinct reverse of the precipitation anomaly between August 1998 and August 2016 is illustrated clearly in Fig. 4a. To describe such precipitation anomaly pattern, we defined a precipitation index (PI) as the difference of August precipitation between the area averages in central China (PI1) and southeastern China (PI2), which are marked by the frames in Fig. 4a from north to south, respectively. Figure $4 \mathrm{~b}$ presents the detrended and normalized time series of PI. The precipitation anomaly pattern associated with the PI displays significant positive (negative) anomaly in central China and negative (positive) anomaly in southeastern China (Fig. 4c). The PI shows the highest positive value in August 1998 and the lowest negative value in 2016 since 1979 (Fig. 4b), which means it can represent the fluctuations of the August precipitation anomaly over eastern China as observed in August 1998 and 2016 (Fig. 3).

The upstream forcing (e.g., Arctic sea ice) plays a potential role in the interannual variability of summer rainfall in East Asia (Enomoto et al. 2003; Wang and $\mathrm{He}$ 2015). These studies motivate us to seek a clue from the Arctic sea ice about the reverse precipitation anomalies in August 1998 and 2016. Li et al. (2015) noted that the influence of different regions' sea ice on East Asia temperature varies. The above-mentioned studies on the relationship between the Arctic sea ice and summer precipitation in China have also focused on different regional sea ice (Zhao et al. 2004; Wu et al. 2009). To identify the key regions where the sea ice variability is closely related to the August precipitation over eastern China, we calculated the correlations between the SIC and the PI during 1979-2016. The results indicate that the SIC anomalies over the north Barents-Kara Seas (BKS) in both July and August are significantly correlated with the PI (Figs. 5a,b). Considering the significant correlation coefficients in July and August, three regions $\left(73^{\circ}-78^{\circ} \mathrm{N}, 20^{\circ}-10^{\circ} \mathrm{W} ; 80^{\circ}-84^{\circ} \mathrm{N}, 10^{\circ}-50^{\circ} \mathrm{E}\right.$; and $77^{\circ}-83^{\circ} \mathrm{N}, 70^{\circ}-90^{\circ} \mathrm{E}$ ) are selected. The sea ice area (SIA) in these three regions is defined as the SIA index, which 
(a)precip anomaly, Jun, 1998

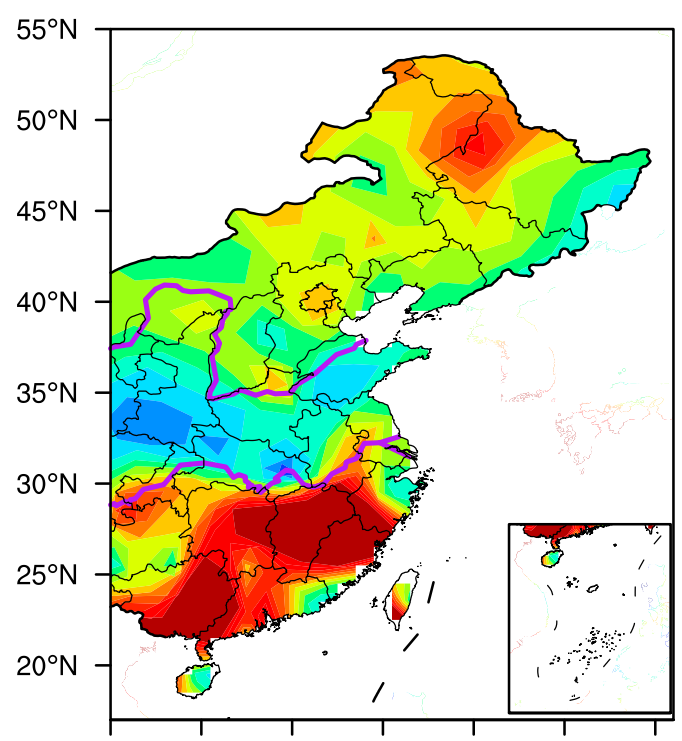

$105^{\circ} \mathrm{E} 110^{\circ} \mathrm{E} 115^{\circ} \mathrm{E} 120^{\circ} \mathrm{E} 125^{\circ} \mathrm{E} 130^{\circ} \mathrm{E} 135^{\circ} \mathrm{E}$

(c)precip anomaly, Jul, 1998

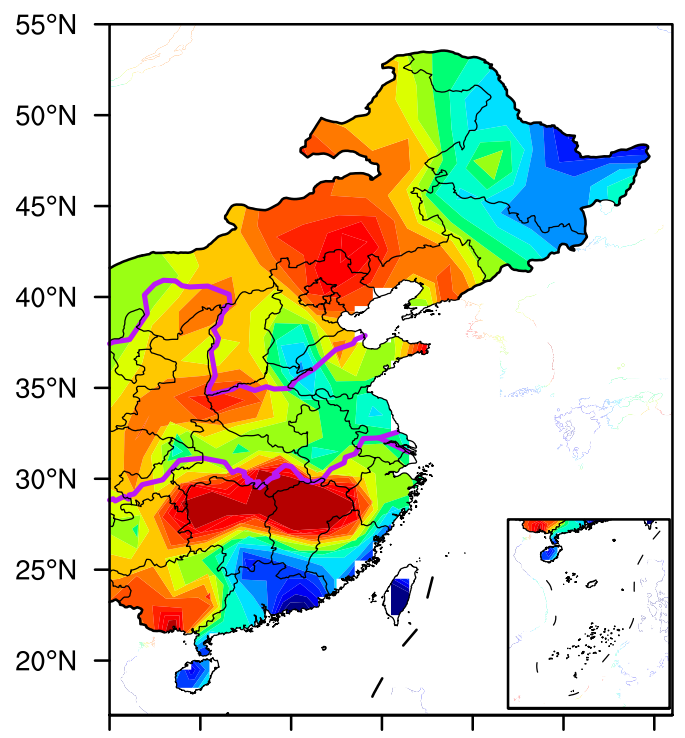

$105^{\circ} \mathrm{E} 110^{\circ} \mathrm{E} 115^{\circ} \mathrm{E} 120^{\circ} \mathrm{E} 125^{\circ} \mathrm{E} 130^{\circ} \mathrm{E} 135^{\circ} \mathrm{E}$ (b)precip anomaly, Jun, 2016

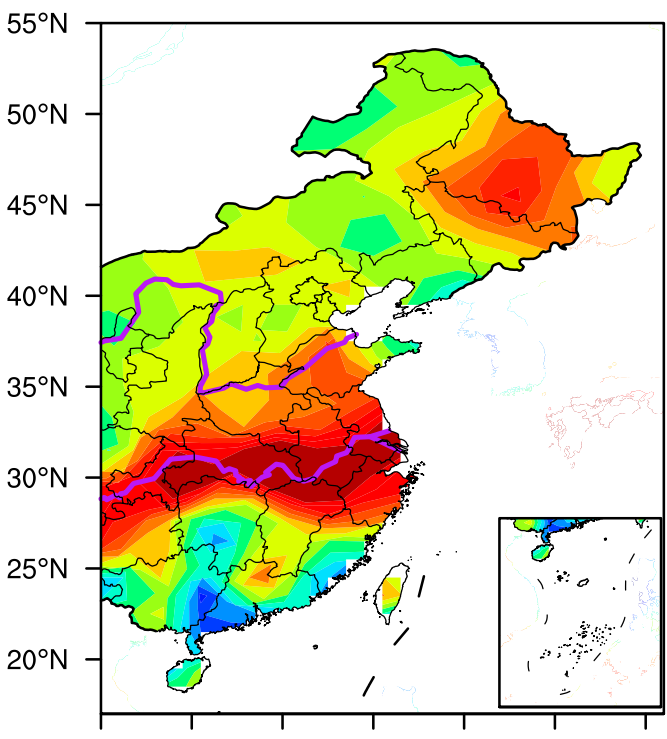

$105^{\circ} \mathrm{E} 110^{\circ} \mathrm{E} 115^{\circ} \mathrm{E} 120^{\circ} \mathrm{E} 125^{\circ} \mathrm{E} 130^{\circ} \mathrm{E} 135^{\circ} \mathrm{E}$

(d)precip anomaly, Jul, 2016

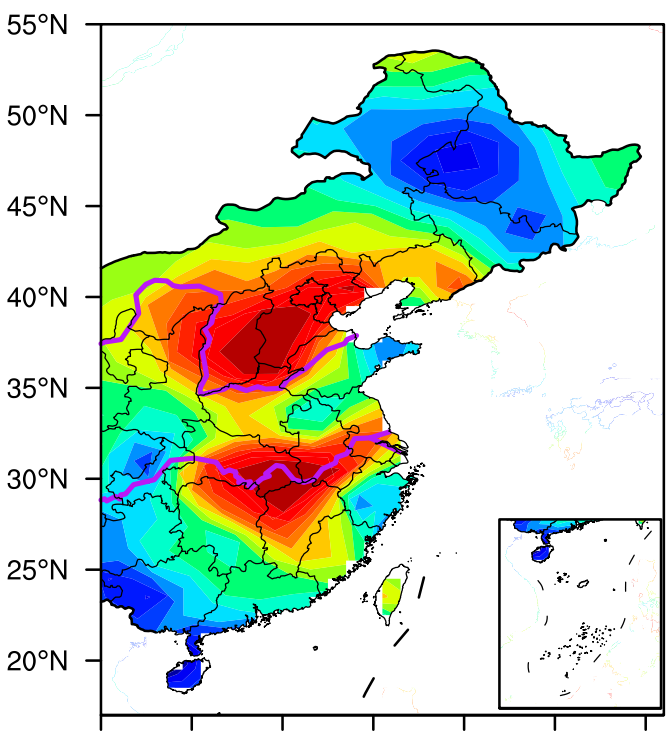

$105^{\circ} \mathrm{E} 110^{\circ} \mathrm{E} 115^{\circ} \mathrm{E} 120^{\circ} \mathrm{E} 125^{\circ} \mathrm{E} 130^{\circ} \mathrm{E} 135^{\circ} \mathrm{E}$ $\mathrm{mm} /$ day

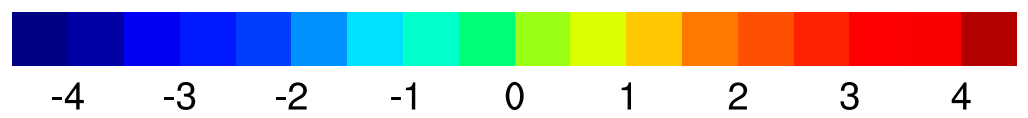

FIG. 2. Distribution of the (a),(b) June and (c),(d) July precipitation anomalies (mm day ${ }^{-1}$ ) in China east of $105^{\circ} \mathrm{E}$ during (a),(c) 1998 and (b),(d) 2016.

is multiplied by -1 so that positive values represent the reduction of sea ice, referred as SIAI. The correlation coefficient of July (August) SIAI with the August PI is $-0.58(-0.59)$, statistically significant at $99 \%$ confidence level (Fig. 5c). To emphasize the potential effect of sea ice on the precipitation, we choose the preceding SIAI (i.e., July) to analyze their relationship. Interestingly, the August precipitation anomaly (Fig. 6) associated with the July SIAI resembles well the precipitation anomaly pattern in August 2016, while it is 
(a)precip anomaly, Aug, 1998, NOAA

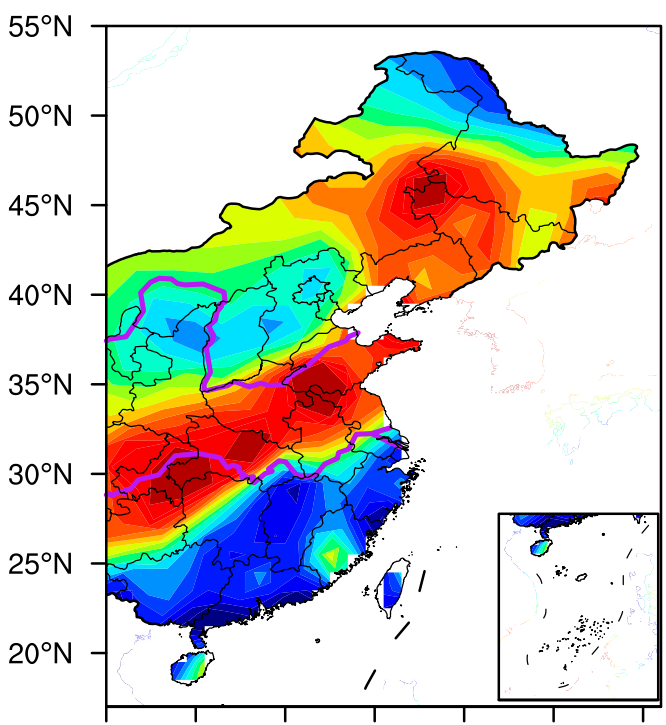

$105^{\circ} \mathrm{E} 110^{\circ} \mathrm{E} 115^{\circ} \mathrm{E} 120^{\circ} \mathrm{E} 125^{\circ} \mathrm{E} 130^{\circ} \mathrm{E} 135^{\circ} \mathrm{E}$

(c)precip anomaly, Aug, 1998, 160 stations

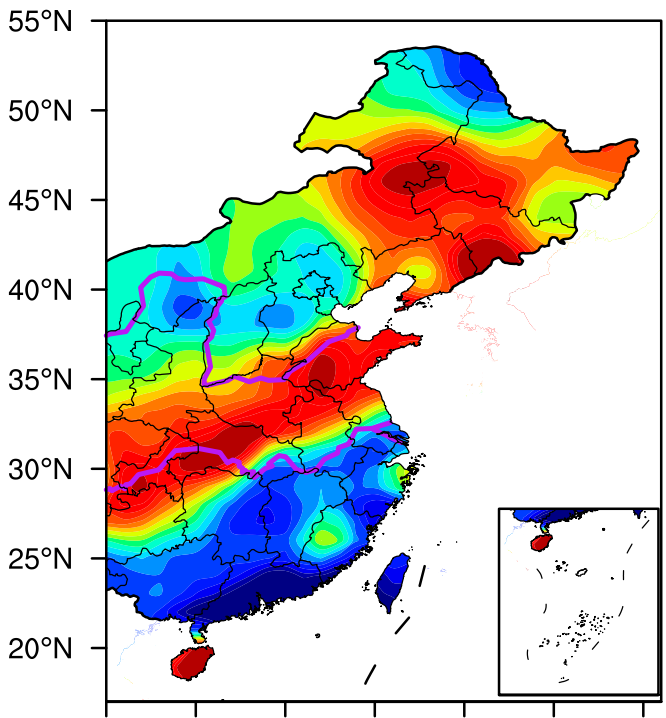

$105^{\circ} \mathrm{E} 110^{\circ} \mathrm{E} 115^{\circ} \mathrm{E} 120^{\circ} \mathrm{E} 125^{\circ} \mathrm{E} 130^{\circ} \mathrm{E} 135^{\circ} \mathrm{E}$ (b)precip anomaly, Aug, 2016, NOAA

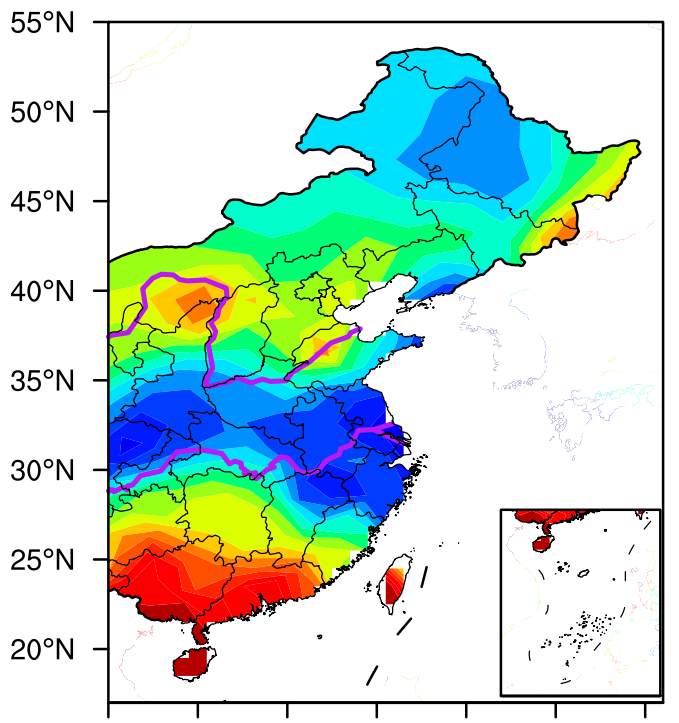

$105^{\circ} \mathrm{E} 110^{\circ} \mathrm{E} 115^{\circ} \mathrm{E} 120^{\circ} \mathrm{E} 125^{\circ} \mathrm{E} 130^{\circ} \mathrm{E} 135^{\circ} \mathrm{E}$

(d)precip anomaly, Aug, 2016, 160 stations

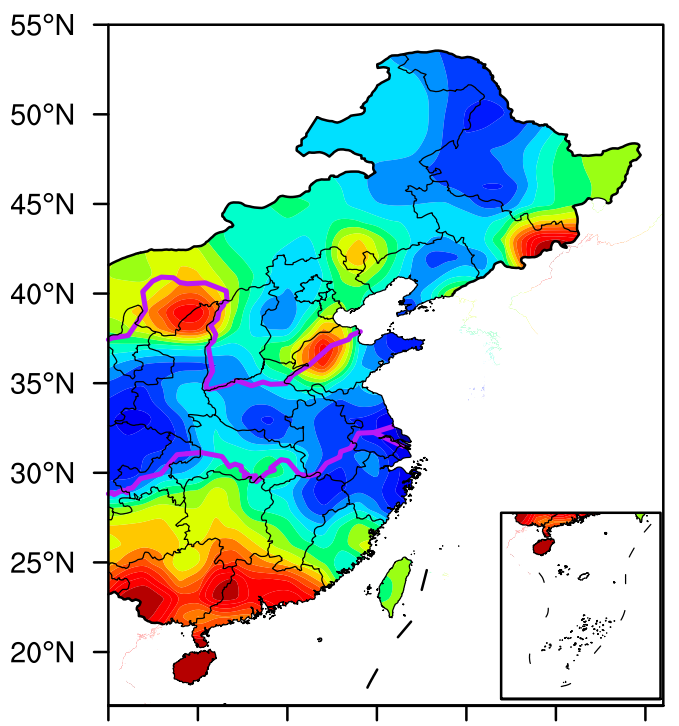

$105^{\circ} \mathrm{E} 110^{\circ} \mathrm{E} 115^{\circ} \mathrm{E} 120^{\circ} \mathrm{E} 125^{\circ} \mathrm{E} 130^{\circ} \mathrm{E} 135^{\circ} \mathrm{E}$ $\mathrm{mm}$ /day

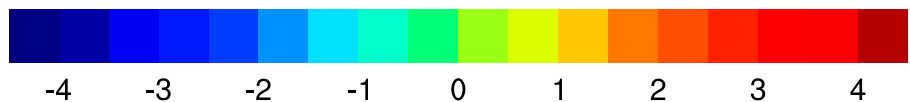

FIG. 3. Distribution of August precipitation anomalies $\left(\mathrm{mm} \mathrm{day}^{-1}\right)$ in China east of $105^{\circ} \mathrm{E}$ during (a),(c) 1998 and (b),(d) 2016. Data are from (a),(b) NOAA and (c),(d) 160 stations from the China Meteorological Administration.

opposite to that in August 1998. This implies that the decreasing of SIA over the BKS might lead to more precipitation in southeastern China and less precipitation in central China.

The anomalous atmospheric circulations associated with the SIAI are further analyzed. Climatologically, southerly (southeasterly or southwesterly) wind prevails over eastern China and transports abundant water vapor from the tropical western Pacific and Indian Ocean in August (He et al. 2018b). Figures 7a and 7b show the $850-\mathrm{hPa}$ wind and vertically integrated water vapor regressed onto the SIAI, respectively. The regression 
(a) Differ. of August precipitation
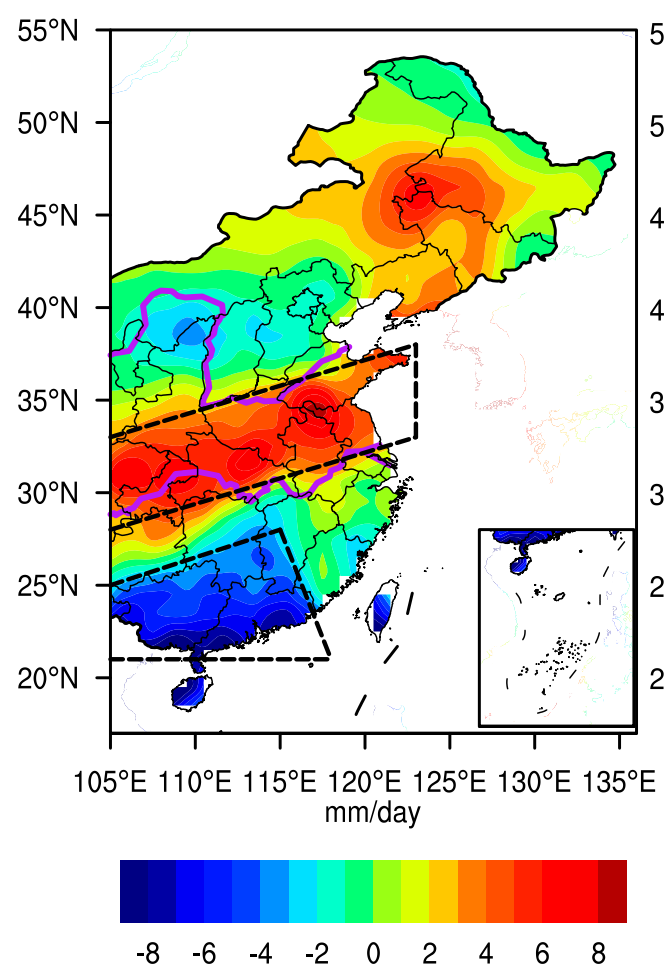

(b) $\mathrm{PI}$ (c) precip, Aug

Corr. with PI
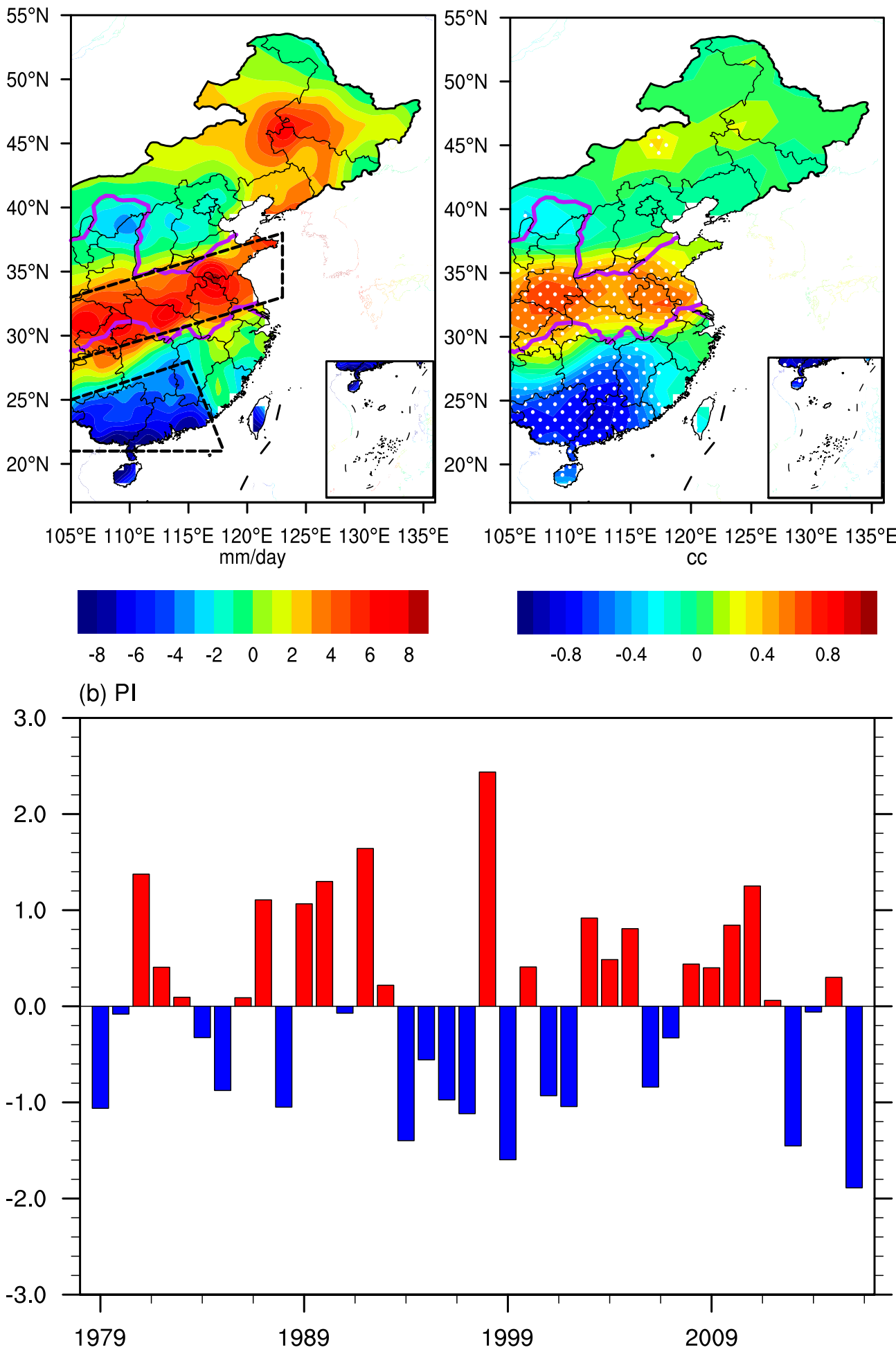

FIG. 4. (a) Difference of August precipitation $\left(\mathrm{mm} \mathrm{day}^{-1}\right.$ ) in China east of $105^{\circ} \mathrm{E}$ between 1998 and 2016. (b) Normalized time series of the PI during August 1979-2016. (c) Correlations of August precipitation with the simultaneous PI. Stippled values are significant at the $90 \%$ confidence level based on the Student's $t$ test. 
(a) SIC ,Ju

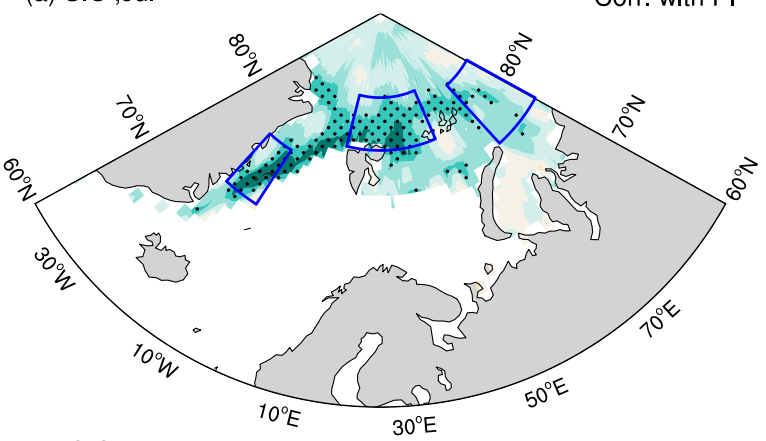

(b) SIC ,Aug

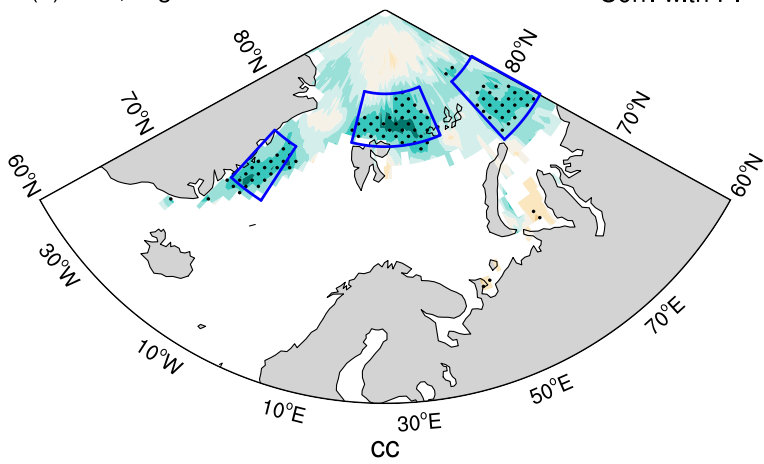

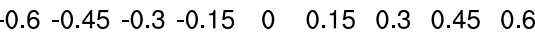
(c) $\mathrm{PI} \& \mathrm{SIAI}$

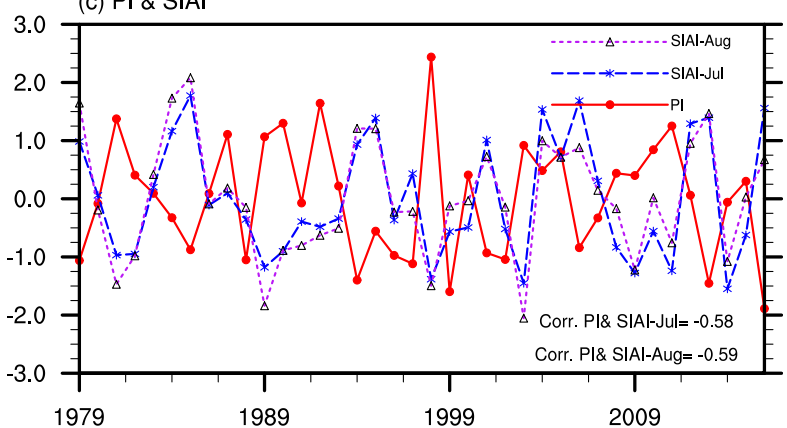

FIG. 5. Correlation maps of sea ice concentration in (a) July and (b) August with regard to the August PI during 1979-2016. Stippled values are significant at the $90 \%$ confidence level based on the Student's $t$ test. (c) Normalized time series of the August PI and SIAI of July and August; the correlation coefficients are given in the lower-right corner.

results indicate that, associated with decreased SIA in the BKS, an anomalous cyclone emerges in southeastern China and the WNP, accompanied with an anomalous anticyclone located over the Korean Peninsula and Japan (Fig. 7a; vectors). Anomalous wind diverges over central China in the lower troposphere, and significantly negative vorticity anomaly appears over central China, the Korean Peninsula, and Japan (Fig. 7a; shading). Meanwhile, significantly positive vorticity anomaly appears in southeastern China (Fig. 7a; shading). The anomalous
Precip., Aug

Corr. with SIAI
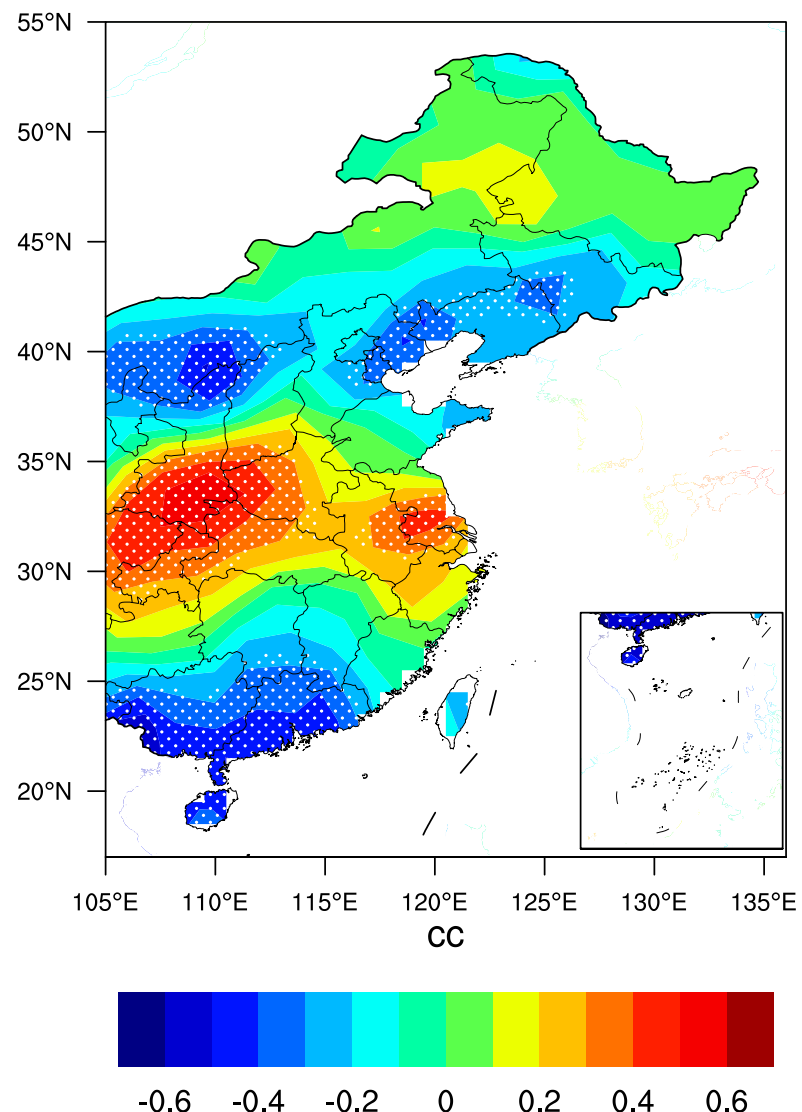

FIG. 6. Correlation map of the August precipitation in China east of $105^{\circ} \mathrm{E}$ with the July SIAI during $1979-2016$. Stippled values are significant at the $90 \%$ confidence level based on the Student's $t$ test.

northerly winds indicate the weakening of the summer monsoon, which causes less water vapor transport to central China. It is further supported by the water vapor flux divergence anomaly in central China accompanied by water vapor flux convergence anomaly in southeastern China (Fig. 7b; shading). In addition, the regression of the vertical cross section for the omega and meridional wind anomalies with regard to the SIAI is shown in Fig. 7c. Since we mainly focus on the precipitation over eastern China, the cross section is averaged from $105^{\circ}$ to $125^{\circ} \mathrm{E}$. It can be seen that significantly anomalous ascending and descending motions occur at around $20^{\circ}$ and $30^{\circ} \mathrm{N}$, which provides unfavorable (favorable) dynamics for the precipitation over central China (southeastern China).

In summary, the variability of the SIA in July over the BKS is significantly correlated with the August precipitation anomaly in eastern China and the related anomalous atmospheric circulation. Additionally, the statistically regressed August precipitation over eastern China with regard to the July SIAI resembles the dipole 

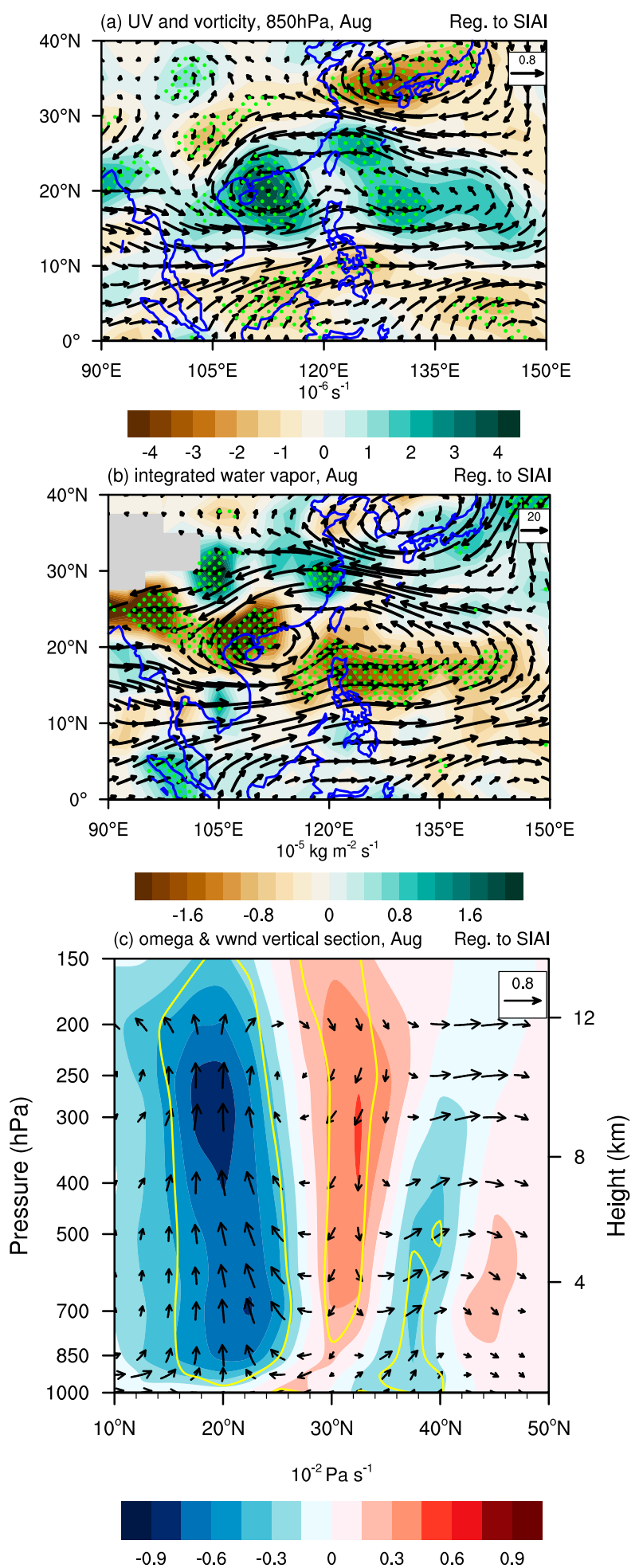

FIG. 7. Regression maps of August (a) 850-hPa wind (vectors; $\mathrm{m} \mathrm{s}^{-1}$ ) and vorticity (shading; $10^{-6} \mathrm{~s}^{-1}$ ) anomalies, (b) vertically integrated water vapor (vectors; $\mathrm{kg} \mathrm{m}^{-1} \mathrm{~s}^{-1}$ ) and water vapor flux divergence (shading; $10^{-5} \mathrm{~kg} \mathrm{~m}^{-2} \mathrm{~s}^{-1}$ ), (c) the vertical cross section averaged along $105^{\circ}-120^{\circ} \mathrm{E}$ for the wind (omega and meridional wind; vectors; $\mathrm{m} \mathrm{s}^{-1}$ ) and omega (shading; $10^{-2} \mathrm{~Pa} \mathrm{~s}^{-1}$ ) anomalies pattern observed in August 2016 well but with opposite sign to the one observed in August 1998.

\section{Physical mechanism on the influence of sea ice over the BKS}

The above discussion suggests the possible upstream forcing on the August precipitation anomaly over eastern China. It implies that, in addition to ENSO, Arctic sea ice should also be taken into account when discussing the variability of the August precipitation anomaly over eastern China. The dynamic process of Arctic sea ice influencing August precipitation over eastern China is addressed in this section, which is important not only for the explanation for the two reverse precipitation anomaly cases but also to provide some theoretical reference for the prediction of August precipitation over eastern China.

Previous studies suggested that the upstream sea ice can influence the atmospheric circulation in eastern China via the Rossby wave in winter (Wang et al. 2015). This motivates us to explore the wave activity flux (WAF) associated with the July SIAI to demonstrate the wave energy propagation and the origin of the atmospheric circulation anomaly (Takaya and Nakamura 2001; Hsu and Lin 2007; Honda et al. 2009). The WAF and meridional wind at $200 \mathrm{hPa}$ regressed onto the SIAI are presented in Fig. 8a. It shows an apparent eastward-pointing flux (vectors) along the subtropical jet stream (at approximately $40^{\circ} \mathrm{N}$ ) with significant negative and positive meridional wind anomalies around $60^{\circ}, 80^{\circ}, 110^{\circ}$, and $150^{\circ} \mathrm{E}$, respectively. The wavelike energy associated with the SIAI disperses along the jet stream in July from the European continent to East Asia. To better depict the propagation of the Rossby wave, we further diagnosed the vertical cross section of the WAF and meridional wind anomalies in July along $40^{\circ} \mathrm{N}$ with regard to the July SIAI (Fig. 8b). The meridional wind anomaly exhibits clear wavelike pattern (shading), especially at the upper troposphere $(200 \mathrm{hPa})$. Meanwhile, the WAF (vectors) propagates from the Caspian Sea to the East Asia (Fig. 8b; vectors). The eastward propagation of the wavelike perturbation along the Asian jet can influence the variation of atmosphere in East Asia through wave energy accumulation (Enomoto et al. 2003; Lee and Ha 2009). Figures $9 \mathrm{a}-\mathrm{d}$ show the barotropic energy conversion (CK) and baroclinic energy conversion (CP) in July

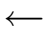

with regard to the July SIAI during 1979-2016. Stippled values in (a) and (b) and those enclosed by the contours in (c) are significant at the $90 \%$ confidence level based on the Student's $t$ test. 
(a) vwnd \& WAF, 200hPa, Jul

Reg. to SIAI
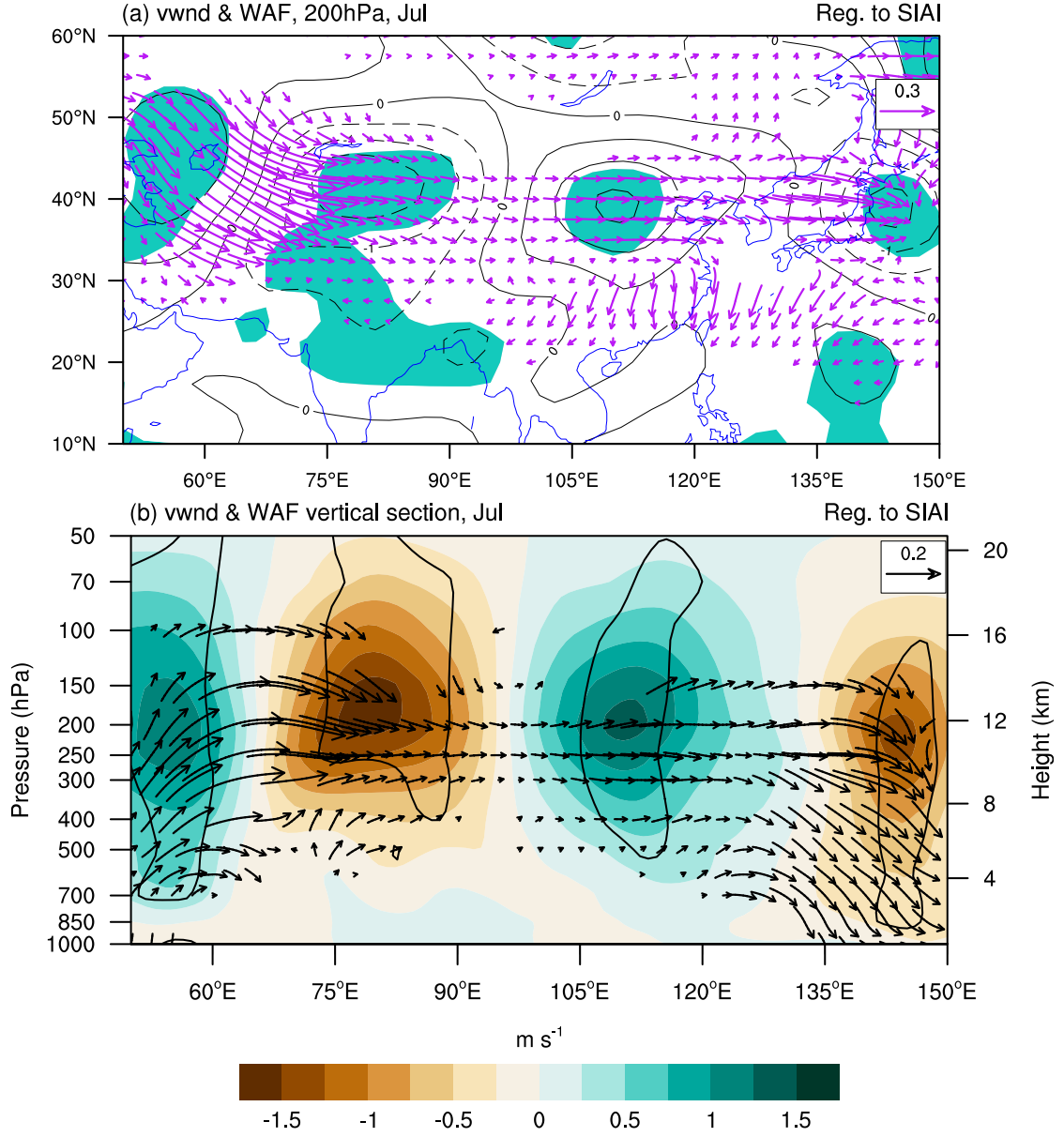

FIG. 8. (a) Regression maps of the July meridional wind (contours; $\mathrm{m} \mathrm{s}^{-1}$ ) and horizontal wave activity flux (vectors; $\mathrm{m}^{2} \mathrm{~s}^{-2}$ ) at $200 \mathrm{hPa}$ and (b) the vertical-zonal cross section averaged along $35^{\circ}-45^{\circ} \mathrm{N}$ for the wave activity flux (vectors, $\mathrm{m}^{2} \mathrm{~s}^{-2}$ ) and meridional wind anomalies (shading; $\mathrm{m} \mathrm{s}^{-1}$ ) with regard to the July SIAI during 1979-2016. Shaded regions in (a) and regions enclosed by contours in (b) indicate that the meridional wind anomalies are significant at the $90 \%$ confidence level based on the Student's $t$ test.

and August with regard to the SIAI. The positive values mean the conversion of kinetic energy from the mean flow to the perturbation anomalies (Kosaka and Nakamura 2006) associated with the July sea ice variability. As shown in Fig. 9a, with regard to the July SIAI, the upper-tropospheric barotropic energy conversion shows a positive center around $35^{\circ} \mathrm{N}$ of East Asia to the southwest of the Korean Peninsula in July where the exit of the subtropical westerly jet is located. Enomoto et al. (2003) suggested that the enhanced Asian jet in August is favorable for the propagation of stationary Rossby waves, which causes the more energy conversion in August. As displayed in Fig. 9c, the abovementioned barotropic energy conversion center is enhanced in August, indicating the accumulation of wave energy from July to August. Furthermore, we calculated the vertically integrated baroclinic energy conversion, which is also apparently stronger in August than that in July (Figs. 9b,d). Actually, the barotropic and baroclinic energy conversion pattern related to the July SIAI resembles well the composited anomalies associated with the PJ pattern (Kosaka and Nakamura 2006; Kosaka et al. 2009), indicating that the wave energy accumulation in East Asia is a potential pathway connecting the upstream sea ice anomalies with the PJ pattern. It can be seen that a clear wavelike pattern at $500 \mathrm{hPa}$ from the subtropical WNP northward to East Asia exhibits in August, with alternate negative and positive height from south to north, which resembles the PJ pattern (Fig. 9e). The PJ pattern further favors the atmospheric circulation of the dipole precipitation anomaly over eastern China (Hsu and Lin 2007; Huang et al. 2012). Such a teleconnection between the sea ice and the precipitation anomaly pattern over the eastern China is also supported by a significant correlation 

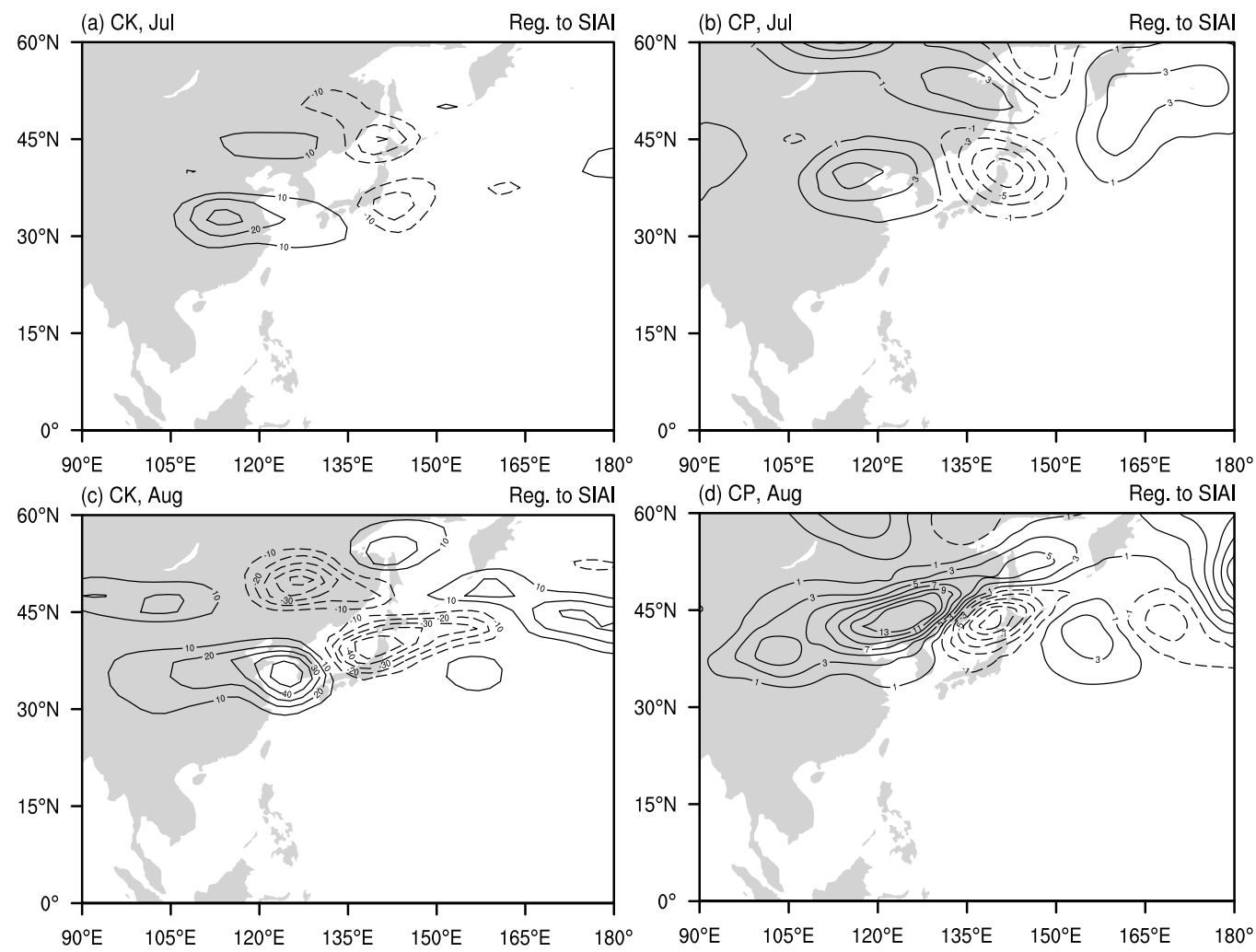

(e) hgt \& WAF, 500hPa, Aug

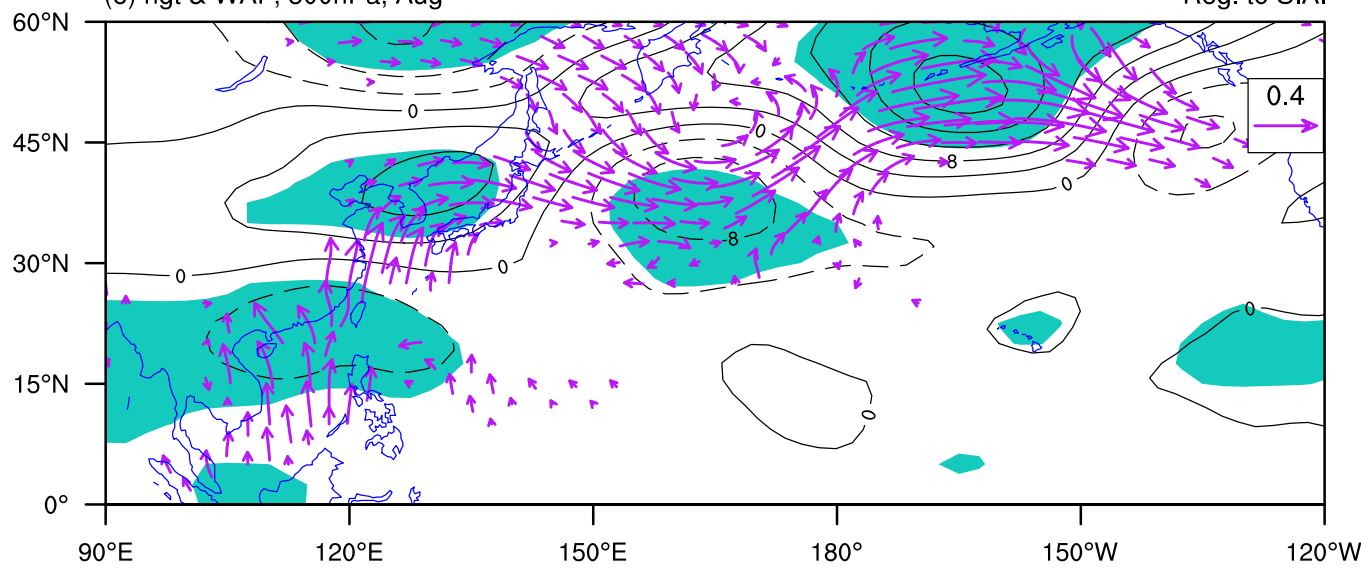

FIG. 9. Regression maps of (a) local barotropic energy conversion $\left(10^{-6} \mathrm{~m}^{2} \mathrm{~s}^{-3}\right)$ at $200 \mathrm{hPa}$ and (b) vertically integrated baroclinic energy conversion $\left(10^{-3} \mathrm{~W} \mathrm{~m}^{-2}\right)$ in July with regard to the July SIAI during 1979-2016. (c),(d) As in (a) and (b), but for August. (e) The 500-hPa wave activity flux (vectors; $\mathrm{m}^{2} \mathrm{~s}^{-2}$ ) and geopotential height (contours; gpm) in August with regard to the July SIAI during 1979-2016. Shaded values are significant at the $90 \%$ confidence level based on the Student's $t$ test.

coefficient of -0.50 (significant at the $99 \%$ confidence level) between the July SIAI and August PJ pattern index (Huang 2004). It should be mentioned that the SIA anomaly may exert effect on the atmospheric circulation through its persistence from July to August. For instance, the August SIAI is highly consistent with the July SIAI with a correlation coefficient of 0.91 and is also similarly correlated with the PI (Fig. 5). The precipitation and atmospheric circulation anomalies associated with the August SIAI are also similar to those related to the July SIAI (figures omitted), but the eastward wavelike activity at midlatitude is weaker in August than that in July. It implies that the July sea ice over the BKS is a potential trigger to the anomalous atmospheric circulation in July-August, and the July sea ice anomaly shows pronounced persistence into August (He et al. 2018a). 

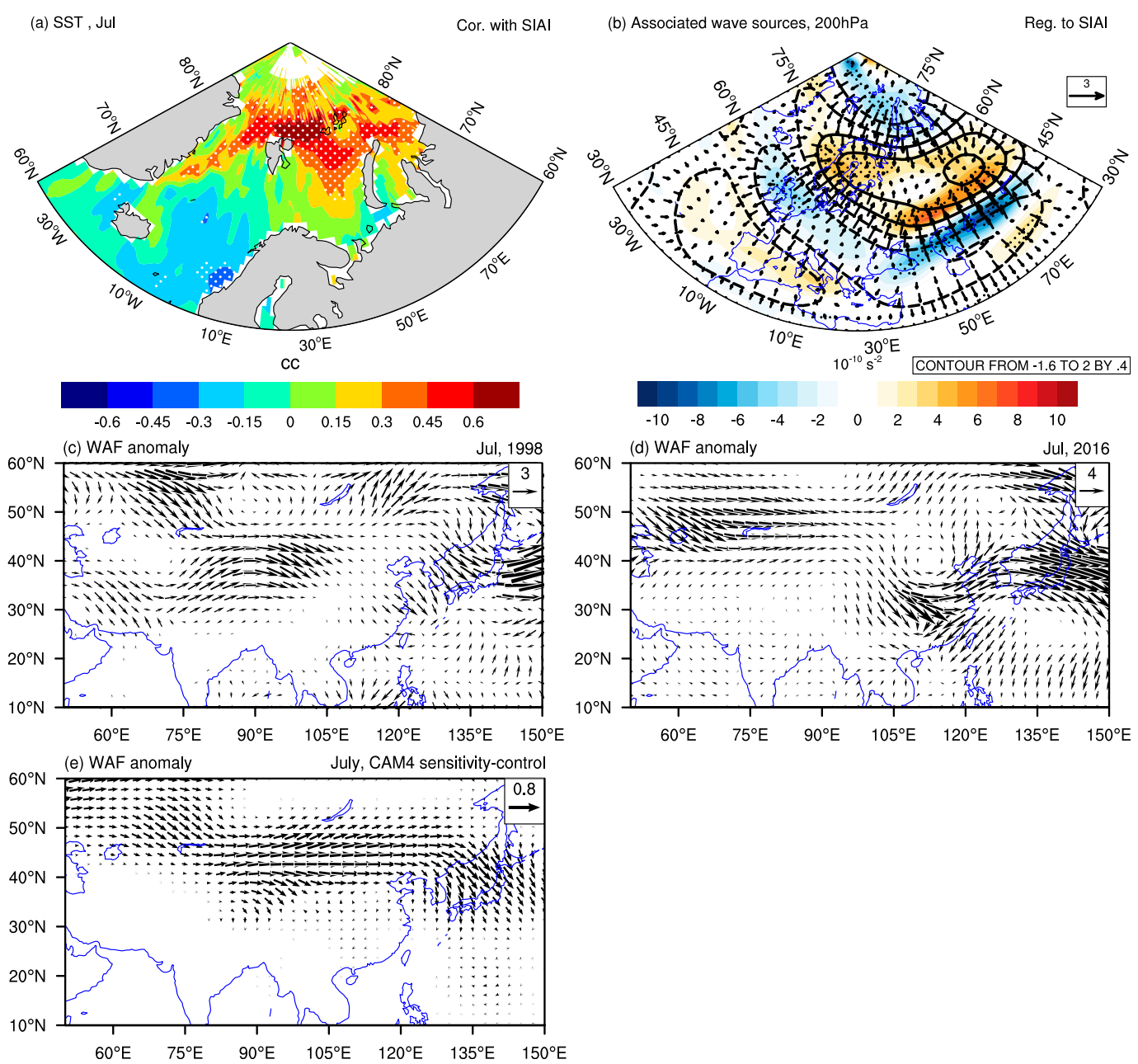

FIG. 10. Correlation maps of (a) the SSTA $\left({ }^{\circ} \mathrm{C}\right.$ ) and (b) Rossby wave sources (shading; $\mathrm{s}^{-2}$ ), velocity potential (contours; $\mathrm{m}^{2} \mathrm{~s}^{-1}$ ), and divergent wind (vectors; $\mathrm{m} \mathrm{s}^{-1}$ ) at $200 \mathrm{hPa}$ in July with the July SIAI during 1979-2016. Stippled values are significant at the $90 \%$ confidence level based on the Student's $t$ test. (c) The 200-hPa wave activity flux (vectors; $\mathrm{m}^{2} \mathrm{~s}^{-2}$ ) anomaly during July in 1998. (d) As in (c), but for 2016. (e) Difference between the sensitivity and control run in CAM4 of the $200-\mathrm{hPa}$ wave activity flux (vectors; $\mathrm{m}^{2} \mathrm{~s}^{-2}$ ) anomaly during July.

Overall, the August precipitation and atmospheric anomalies in eastern China can retrospect to the Rossby wave activity at midlatitudes on the Eurasian continent. As to the excitation mechanism of the wave activity, earlier work mainly focused on the tropical heating anomaly, for example, the Indian summer monsoon heating (Ding and Wang 2005; Ding et al. 2011; Chen and Huang 2012). To discuss the excitation of the midlatitude wavelike pattern associated with the sea ice over the BKS, the Rossby wave sources [defined as $-\nabla \cdot \mathbf{V}_{x}(f+\zeta)$ by Sardeshmukh and Hoskins 1988] are taken into consideration. Corresponding to the reduced SIA, the SSTA over the BKS is significantly positive (Fig. 10a), which may induce anomalous atmospheric circulation via changing local thermal conditions. The divergent wind and velocity potential are calculated to illustrate the dynamical relationship between the heating anomaly and the flow. As displayed in Fig. 10b, with the positive SSTA, anomalous divergent wind emerges at the upper troposphere, accompanied by the negative velocity potential anomaly. The divergence in the polar region can trigger the rotational component by the vorticity stretching term. The rotational component may disperse south by the divergent wind and causes the vorticity generation at midlatitude, which leads to the anomalous convergent flow and positive velocity potential anomaly over the Europe. The advection of vorticity by the anomalous divergent and convergent flows is used to locate the position of the Rossby wave sources (Sardeshmukh and Hoskins 1988; Chen and Huang 2012), which are related to the wavelike pattern over Eurasia. Meanwhile, it is depicted that there 
are significantly positive wave sources over high $\left(60^{\circ} \mathrm{N}\right)$ and middle $\left(45^{\circ} \mathrm{N}\right)$ latitudes of the Europe (Fig. 10b; shading). Therefore, the wave sources associated with the eastward wavelike activity are located over the Europe and excited by the thermal anomaly over the BKS. The zonal wave activity during July can be also seen in 1998 and 2016 cases. From the wave activity flux anomaly (Figs. 10c,d), it can be seen that the wave activity disperses from the high latitudes of the European continent, which is consistent with the location of the Rossby wave sources. The wave train then propagates eastward along the subtropical jet $\left(40^{\circ} \mathrm{N}\right)$ to the East Asia. In the two cases, the Rossby wave dispersion over Eurasia is analogous, coincident with the regression results.

To further confirm the teleconnection of the sea ice over the BKS and the related atmospheric circulation downstream in July and August, model simulations (CAM4) are also employed. Two numerical experiments are conducted in this study: a control experiment and a sea ice sensitivity experiment. The sea ice concentration is prescribed as boundary conditions in the model and other external variables are fixed. In the control run, 60-yr experiments are simulated forced by climatological condition of the sea ice concentration and the latter 50-yr ensemble mean is used as the results of the control experiment considered of the model uncertainty. As to the sea ice sensitivity experiment, the sea ice concentration is reduced in July and August over the BKS (same three regions in Fig. 5), while other months are prescribed by the climatology. The sea ice concentration reduction is calculated by the observations with the averaged difference between the high-and low-SIAI years (based on one standard deviation). As in the control experiment, 50-yr simulation outcomes are obtained. Actually, the 50-yr results cannot be regarded as continuous years, but rather as 50 independent experiments with different initial values. We employ 30 sensitivity experiment results and compare them with the control run results to reveal the connections of the sea ice anomaly and the downstream atmospheric circulation in August.

First, the wave activity over Eurasia during July is examined in the model experiment. The WAF anomaly shows the apparent eastward dispersion of the Rossby wave from the high latitudes of Europe to East Asia corresponding to anomalous Arctic sea ice (Fig. 10e), which is consistent with the observation. Furthermore, it is indicated from the observational analyses that the anomalous cyclone and anticyclone over East Asia directly modulate the precipitation anomaly in eastern China. In the model simulation, the differences between the control run and sensitivity experiment in $850-\mathrm{hPa}$ wind and integrated water vapor transport are presented in Fig. 11. It is shown that, associated with reduced sea ice concentration over the BKS, an apparent anomalous cyclone emerges in southeastern China and western Pacific while an anomalous anticyclone appears in the Korean Peninsula and Japan in August at $850-\mathrm{hPa}$, which is consistent with the observational regression results (Fig. 7a). The divergent wind causes the water vapor divergence anomaly in central China, which is accompanied by the water vapor convergence anomaly over southeastern China (Fig. 11b). Meanwhile, the significant negative height anomaly appears in southeastern China and western Pacific while the significant positive anomaly emerges near the Korean Peninsula and Japan in August (Fig. 11c; contours), indicating the formation of the PJ pattern (Enomoto et al. 2003; Lee and Ha 2009). The wavelike pattern propagating from the subtropical WNP northward to East Asia is more obvious by inspecting the wave activity flux in August at $500 \mathrm{hPa}$ (Fig. 11c; vectors). Therefore, the model simulations support the speculation that the reduced SIA in the BKS may lead to more precipitation over southern China and less precipitation over central China in August.

Finally, we backtrack to the sea ice anomaly and the circulation of 1998 and 2016 cases (Fig. 12). The SIA anomalies in the BKS are positive in July 1998 (Fig. 12a). The vertical motions in the cross section averaged along $105^{\circ}-120^{\circ} \mathrm{E}$ show anomalous ascending motion around $30^{\circ}-35^{\circ} \mathrm{N}$ and descending motion in south to $30^{\circ} \mathrm{N}$ in August 1998 (Fig. 12c). The anomalous anticyclone emerges at the lower troposphere over the western Pacific (Fig. 12e), and the south wind component brings abundant water vapor to central China. As for August 2016, the SIA anomalies are negative (Fig. 12b), opposite to those in July 1998. Correspondingly, anomalous ascending motion occurs between $20^{\circ}$ and $25^{\circ} \mathrm{N}$ and descending motion appears north to $30^{\circ} \mathrm{N}$. In addition, anomalous northerly wind prevails in central China (Fig. 12f), which indicates the weakening of the summer monsoon and causes less water vapor transport to central China. Overall, the observed atmospheric anomalies in 1998 (2016), which are concurrent with a positive (negative) July SIA anomaly in the BKS, are consistent with the statistically regressed ones with regard to the corresponding SIA variability in the BKS. These results confirm the potential impact of the Arctic sea ice on the August precipitation over eastern China.

\section{Summary and discussion}

Both 1997/98 and 2015/16 saw super-El Niño events (Shao and Zhou 2016; Zhai et al. 2016). Meanwhile, the peak intensity and decay conditions of the two super episodes are similar. The total rainfall in eastern China during the summers of 1998 and 2016 increased remarkably 

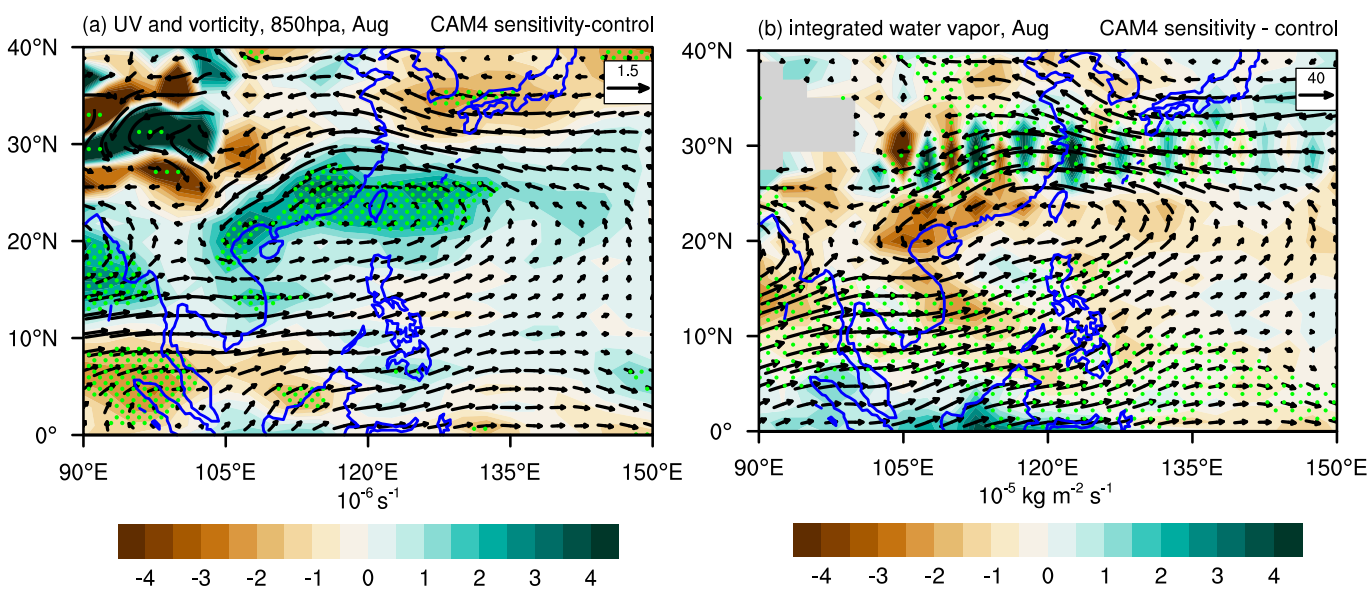

(c) hgt \& WAF, 500hPa, Aug

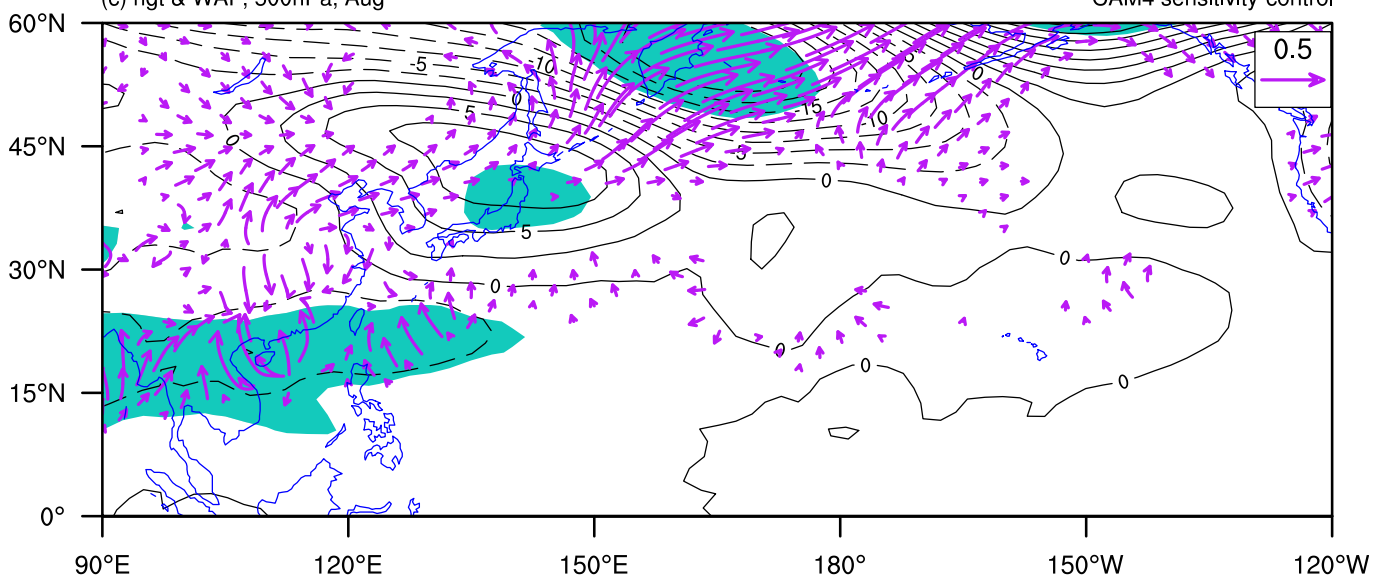

FIG. 11. The difference between the sensitivity and control run in CAM4 of the August (a) 850-hPa wind (vectors; $\mathrm{m} \mathrm{s}^{-1}$ ) and vorticity (shading; $10^{-6} \mathrm{~s}^{-1}$ ), (b) vertically integrated water vapor (vectors; $\mathrm{kg} \mathrm{m}^{-1} \mathrm{~s}^{-1}$ ) and water vapor flux divergence (shading; $10^{-5} \mathrm{~kg} \mathrm{~m}^{-2} \mathrm{~s}^{-1}$ ), and (c) 500-hPa geopotential height (contours; gpm) and the associated wave activity flux (vectors; $\mathrm{m}^{2} \mathrm{~s}^{-2}$ ). Stippled values in (a) and (b) and shaded regions in (c) are significant at the $90 \%$ confidence level based on the Student's $t$ test.

as expected. Additionally, the June and July rainfall anomalies in 1998 and 2016 also exhibit many similarities under the influence of the similar super-El Niño events, which is reasonable according to the previous studies (e.g., Wang et al. 2000; Xie et al. 2009). However, the August precipitation anomalies between the two years show nearly reverse patterns. The mechanism of the reverse August precipitation anomalies over eastern China between 1998 and 2016 under similar El Niño conditions is investigated in this study.

The August precipitation anomalies in 1998 and 2016 exhibit a dipole pattern but with opposite sign over eastern China, that is, notable increasing (decreasing) over central China (approximately $30^{\circ}-35^{\circ} \mathrm{N}$ ) and decreasing (increasing) over southeastern China (approximately south of $25^{\circ} \mathrm{N}$ ). Statistical analyses reveal that such a dipole rainfall pattern over eastern China in August is concurrent with pronounced SIC anomalies over the
BKS in July and August. Therefore, the July SIAI is defined to diagnose the potential influence of sea ice on the precipitation over eastern China. It is found that with regard to the reduced SIA in July over the BKS, the thermal condition of the underlying surface changes. The positive SSTA in the polar region stimulates significant divergence anomaly at the upper troposphere, which leads to the rotational component and the vorticity generation (Chen and Huang 2012). Consequently, anomalous upper-level convergence emerges over the Caspian Sea. The advections of vorticity anomaly by the anomalous divergent flow place the effective Rossby wave sources (Sardeshmukh and Hoskins 1988) to the equator and apparent positive Rossby wave sources emerge over Europe. As a result, the Rossby wavetrain propagates from Europe eastward to East Asia. Because of the eastward propagation of the Rossby wave activity, significantly positive barotropic and 

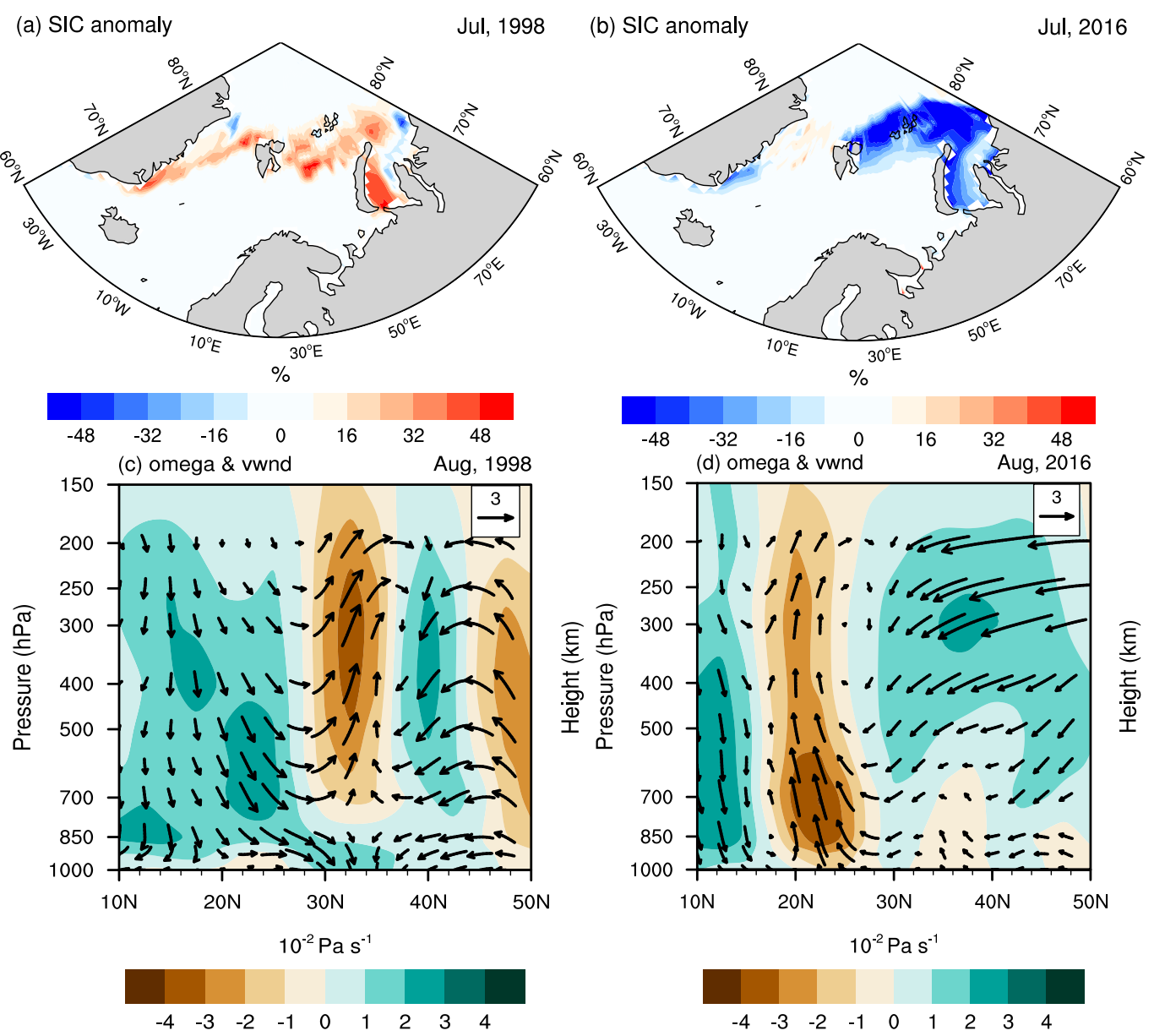

(e) UV850 anomaly Aug, 1998
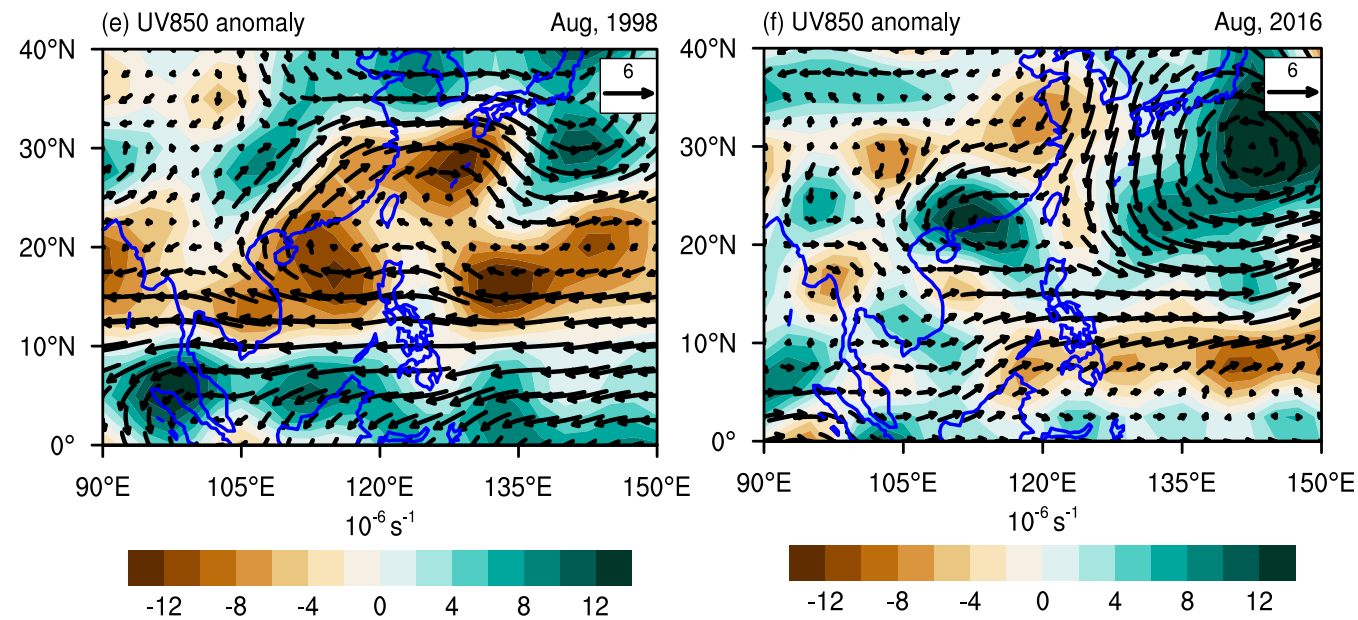

FIG. 12. Sea ice concentration (\%) anomaly in (a) July 1998 and (b) July 2016. Vertical wind (omega and meridional wind; vectors; $\mathrm{m} \mathrm{s}^{-1}$ ) and omega (shading; $10^{-2} \mathrm{~Pa} \mathrm{~s}^{-1}$ ) anomalies for the cross section averaged along $105^{\circ}-120^{\circ} \mathrm{E}$ in (c) August 1998 and (d) August 2016. Wind (vectors; $\mathrm{m} \mathrm{s}^{-1}$ ) and vorticity (shading; $10^{-6} \mathrm{~s}^{-1}$ ) anomalies at 850-hPa in (e) August 1998 and (f) August 2016.

baroclinic energy conversion occurs in the jet exit region near the Korean Peninsula in August, which resembles well the composited anomalies associated with the PJ pattern (Kosaka and Nakamura 2006; Kosaka et al. 2009).
It implies that the perturbation energy accumulation in East Asia stimulates the formation of the PJ pattern, which favors the dipole rainfall anomaly pattern over eastern China (Hsu and Lin 2007). 
Numerical experiments are employed to verify the results of the observational analyses. As indicated by the model results, associated with the reduced sea ice over the BKS, significant anomalous cyclone and anticyclone appear in August in the subtropical western Pacific and near the Korean Peninsula/Japan, respectively. Meanwhile, the spatial pattern of the simulated height anomalies over the Korean Peninsula and Japan and the western Pacific resembles the PJ pattern that is identified by the regressing onto the July SIAI. Therefore, both observational and numerical analyses suggest that the sea ice anomaly over the BKS may modulate the atmospheric circulation and precipitation in eastern China during August.

The spatial distribution of the observed rainfall anomaly over eastern China and the anomalous large-scale atmospheric circulation in August 2016 (1998) largely resemble (mirror) the regressed ones with regard to the July SIAI over the BKS. Thus, the observed positive (negative) SIA anomaly over the BKS in August 1998 (2016) suggests the potential contribution of the upstream sea ice to the reverse August precipitation anomalies in eastern China between 1998 and 2016 synchronizing with strong El Niño events.

It is usually considered that there is a close connection between the rainfall in eastern China and the simultaneous Pacific SSTA (e.g., Li et al. 2017). Several studies pointed out some differences in the atmosphere and ocean between these two years. Guo et al. (2016) pointed out that the SST is colder over the region east to Japan during August 2016 than during August 1998. Another study suggested that the Madden-Julian oscillation was extremely active in the western Pacific for 25 days, which triggered more tropical cyclones and further influenced the significant turning of tropical and subtropical circulations in August 2016. The MJO was active over the tropical Indian Ocean in August 1998, which is conducive to the maintenance of a strong western Pacific subtropical high in 1998, which caused the precipitation anomaly in eastern China (Yuan et al. 2017). On the one hand, these studies have explained the precipitation differences between these two years. On the other hand, the results revealed by our study imply that, in addition to ENSO's impact, the effect of the interannual variability of upstream sea ice should be taken into account when predicting the subseasonal summer, especially August rainfall in eastern China. Moreover, the mechanism of the diversity of monthly summer rainfall in eastern China requires more investigation.

Acknowledgments. This research was supported by the National Key R\&D Program of China (2016YFA0600703) and the National Natural Science Foundation of China
(Grants 41875118, 41605059, 41505073, and 41421004), the CONNECTED supported by UTFORSK Partnership Program (UTF-2016-long-term/10030), and the Young Talent Support Program by China Association for Science and Technology (Grant 2016QNRC001).

\section{REFERENCES}

Chen, G., and R. Huang, 2012: Excitation mechanisms of the teleconnection patterns affecting the July precipitation in northwest China. J. Climate, 25, 7834-7851, https://doi.org/ 10.1175/JCLI-D-11-00684.1.

Chen, L.-L., O. M. Johannessen, K. Khvorostovsky, and H.-J. Wang, 2009: Greenland Ice Sheet elevation change in winter and influence of atmospheric teleconnections in the Northern Hemisphere. Atmos. Ocean. Sci. Lett., 2, 376-380, https:// doi.org/10.1080/16742834.2009.11446826.

Chen, M., P. Xie, J. E. Janowiak, and P. A. Arkin, 2002: Global land precipitation: A 50-yr monthly analysis based on gauge observations. J. Hydrometeor., 3, 249-266, https://doi.org/ 10.1175/1525-7541(2002)003<0249:GLPAYM>2.0.CO;2.

Chen, X., and T. Zhou, 2014: Relative role of tropical SST forcing in the 1990s periodicity change of the Pacific-Japan pattern interannual variability. J. Geophys. Res. Atmos., 119, $13043-$ 13 066, https://doi.org/10.1002/2014JD022064.

Ding, Q., and B. Wang, 2005: Circumglobal teleconnection in the Northern Hemisphere summer. J. Climate, 18, 3483-3505, https://doi.org/10.1175/JCLI3473.1.

—_ — - J. M. Wallace, and G. Branstator, 2011: Tropicalextratropical teleconnections in boreal summer: Observed interannual variability. J. Climate, 24, 1878-1896, https://doi.org/ 10.1175/2011JCLI3621.1.

Ding, Y., Z. Wang, and Y. Sun, 2008: Inter-decadal variation of the summer precipitation in East China and its association with decreasing Asian summer monsoon. Part I: Observed evidences. Int. J. Climatol., 28, 1139-1161, https://doi.org/ 10.1002/joc.1615.

Enomoto, T., B. J. Hoskins, and Y. Matsuda, 2003: The formation mechanism of the Bonin high in August. Quart. J. Roy. Meteor. Soc., 129, 157-178, https://doi.org/10.1256/qj.01.211.

Feng, J., W. Chen, C. Y. Tam, and W. Zhou, 2011: Different impacts of El Niño and El Niño Modoki on China rainfall in the decaying phases. Int. J. Climatol., 31, 2091-2101, https:// doi.org/10.1002/joc. 2217 .

Guo, D., Y. Gao, I. Bethke, D. Gong, O. M. Johannessen, and H. Wang, 2014: Mechanism on how the spring Arctic sea ice impacts the East Asian summer monsoon. Theor. Appl. Climatol., 115, 107-119, https://doi.org/10.1007/s00704-013-0872-6.

—, L. Wang, Z. Li, Y. Su, H. Qin, and Y. Huang, 2016: Comparison between anomalies of summer rainfall in China in decaying years during super El Niño events of 2015/2016 and 1997/1998 (in Chinese). Trans. Atmos. Sci., 39, 835-844.

Han, J., and R. Zhang, 2009: The dipole mode of the summer rainfall over East China during 1958-2001. Adv. Atmos. Sci., 26, 727-735, https://doi.org/10.1007/s00376-009-9014-6.

He, C., A. Lin, D. Gu, C. Li, B. Zheng, and T. Zhou, 2017: Interannual variability of eastern China summer rainfall: The origins of the meridional triple and dipole modes. Climate Dyn., 48, 683-696, https://doi.org/10.1007/s00382016-3103-x.

He, S., E. M. Knudsen, D. W. J. Thompson, and T. Furevik, 2018a: Evidence for predictive skill of high-latitude climate due to 
midsummer sea ice extent anomalies. Geophys. Res. Lett., 45, 9114-9122, https://doi.org/10.1029/2018GL078281.

_, Y. Gao, T. Furevik, H. Wang, and F. Li, 2018b: Teleconnection between sea ice in the Barents Sea in June and the Silk Road, Pacific-Japan and East Asian rainfall patterns in August. Adv. Atmos. Sci., 35, 52-64, https://doi.org/10.1007/ s00376-017-7029-y.

Honda, M., J. Inoue, and S. Yamane, 2009: Influence of low Arctic sea ice minima on anomalously cold Eurasian winters. Geophys. Res. Lett., 36, L08707, https://doi.org/10.1029/ 2008GL037079.

Hoskins, B. J., I. N. James, and G. H. White, 1983: The shape, propagation and mean-flow interaction of large-scale weather systems. J. Atmos. Sci., 40, 1595-1612, https://doi.org/10.1175/ 1520-0469(1983)040<1595:TSPAMF > 2.0.CO;2.

Hsu, H.-H., and S.-M. Lin, 2007: Asymmetry of the tripole rainfall pattern during the East Asian summer. J. Climate, 20, 44434458, https://doi.org/10.1175/JCLI4246.1.

Hu, K., and G. Huang, 2010: The formation of precipitation anomaly patterns during the developing and decaying phases of ENSO. Atmos. Ocean. Sci. Lett., 3, 25-30, https://doi.org/ 10.1080/16742834.2010.11446839.

Huang, G., 2004: An index measuring the interannual variation of the East Asian summer monsoon-The EAP index. $A d v$. Atmos. Sci., 21, 41-52, https://doi.org/10.1007/BF02915679.

Huang, P., and R. Huang, 2010: Effects of El Niño events on intraseasonal variations of following summer rainfall in China and its mechanism (in Chinese). Trans. Atmos. Sci., 33, 513-519.

Huang, R., and Y. Wu, 1989: The influence of ENSO on the summer climate change in China and its mechanism. Adv. Atmos. Sci., 6, 21-32, https://doi.org/10.1007/BF02656915.

- W. Chen, B. Yan, and R. Zhang, 2004: Recent advances in studies of the interaction between the East Asian winter and summer monsoons and ENSO cycle. Adv. Atmos. Sci., 21, 407-424, https://doi.org/10.1007/BF02915568.

— cesses, and causes of the spatio-temporal variabilities of the East Asian monsoon system. Adv. Atmos. Sci., 29, 910-942, https://doi.org/10.1007/s00376-012-2015-x.

Jin, D., S. N. Hameed, and L. Huo, 2016: Recent changes in ENSO teleconnection over the western Pacific impacts the eastern China precipitation dipole. J. Climate, 29, 7587-7598, https:// doi.org/10.1175/JCLI-D-16-0235.1.

Jin, Z., and S. Tao, 1999: A study on the relationships between ENSO cycle and rainfalls during summer and winter in eastern China (in Chinese). Chin. J. Atmos. Sci., 23, 663-672.

Kalnay, E., and Coauthors, 1996: The NCEP/NCAR 40-Year Reanalysis Project. Bull. Amer. Meteor. Soc., 77, 437-471, https:// doi.org/10.1175/1520-0477(1996)077<0437:TNYRP>2.0.CO;2.

Kosaka, Y., and H. Nakamura, 2006: Structure and dynamics of the summertime Pacific-Japan teleconnection pattern. Quart. J. Roy. Meteor. Soc., 132, 2009-2030, https://doi.org/10.1256/ qj.05.204.

,,-- M. Watanabe, and M. Kimoto, 2009: Analysis on the dynamics of a wave-like teleconnection pattern along the summertime Asian jet based on a reanalysis dataset and climate model simulations. J. Meteor. Soc. Japan, 87, 561-580, https://doi.org/10.2151/jmsj.87.561.

Lau, K. M., and H. Weng, 2001: Coherent modes of global SST and summer rainfall over China: An assessment of the regional impacts of the 1997-98 El Niño. J. Climate, 14, 1294-1308, https://doi.org/10.1175/1520-0442(2001)014<1294:CMOGSA> 2.0.CO;2.
Lee, S., and K. Ha, 2009: Eddy-mean flow interaction and its association with Bonin high: Comparison of July and August. Asia-Pac. J. Atmos. Sci., 45, 483-498.

Li, B., and T. Zhou, 2011: El Niño-Southern Oscillation-related principal interannual variability modes of early and late summer rainfall over East Asia in sea surface temperaturedriven AGCM simulations. J. Geophys. Res., 116, D14118, https://doi.org/10.1029/2011JD015691.

Li, F., H.-J. Wang, and Y.-Q. Gao, 2015: Change in sea ice cover is responsible for non-uniform variation in winter temperature over East Asia. Atmos. Ocean. Sci. Lett., 8, 376-382, https:// doi.org/10.3878/AOSL20150039.

Li, H.-X., H.-P. Chen, and H.-J. Wang, 2017: Influence of North Pacific SST on heavy precipitation events in autumn over North China. Atmos. Ocean. Sci. Lett., 10, 21-28, https://doi.org/ 10.1080/16742834.2017.1237256.

Li, L., W. Li, Q. Tang, P. Zhang, and Y. Liu, 2016: Warm season heavy rainfall events over the Huaihe River valley and their linkage with wintertime thermal condition of the tropical oceans. Climate Dyn., 46, 71-82, https://doi.org/10.1007/ s00382-015-2569-2.

Li, X., and P. Zhai, 2000: On indices and indicators of ENSO episodes (in Chinese). Acta Meteor. Sin., 58, 102-109.

— W. Zhou, D. Chen, C. Li, and J. Song, 2014: Water vapor transport and moisture budget over eastern China: Remote forcing from the two types of El Niño. J. Climate, 27, 87788792, https://doi.org/10.1175/JCLI-D-14-00049.1.

Lin, Z.-D., and F. Li, 2018: Impact of interannual variations of spring sea ice in the Barents Sea on East Asian rainfall in June. Atmos. Ocean. Sci. Lett., 11, 275-281, https://doi.org/10.1080/ 16742834.2018.1454249.

Liu, J., J. A. Curry, H. Wang, M. Song, and R. M. Horton, 2012: Impact of declining Arctic sea ice on winter snowfall. Proc. Natl. Acad. Sci. USA, 109, 4074-4079, https://doi.org/10.1073/ pnas.1114910109.

Liu, Y., K. Fan, and H. Wang, 2011: Statistical downscaling prediction of summer precipitation in southeastern China. Atmos. Ocean. Sci. Lett., 4, 173-180, https://doi.org/10.1080/ 16742834.2011.11446925.

Nitta, T., 1987: Convective activities in the tropical western Pacific and their impact on the Northern Hemisphere summer circulation. J. Meteor. Soc. Japan, 65, 373-390, https://doi.org/ 10.2151/jmsj1965.65.3_373.

_ , and Z.-Z. Hu, 1996: Summer climate variability in China and its association with $500 \mathrm{hPa}$ height and tropical convection. J. Meteor. Soc. Japan, 74, 425-445, https://doi.org/10.2151/ jmsj1965.74.4_425.

Rayner, N., D. E. Parker, E. B. Horton, C. K. Folland, L. V. Alexander, D. P. Rowell, E. C. Kent, and A. Kaplan, 2003: Global analyses of sea surface temperature, sea ice, and night marine air temperature since the late nineteenth century. J. Geophys. Res., 108, 4407, https://doi.org/10.1029/2002JD002670.

Sardeshmukh, P. D., and B. J. Hoskins, 1988: The generation of global rotational flow by steady idealized tropical divergence. J. Atmos. Sci., 45, 1228-1251, https://doi.org/10.1175/15200469(1988)045<1228:TGOGRF>2.0.CO;2.

Screen, J. A., 2013: Influence of Arctic sea ice on European summer precipitation. Environ. Res. Lett., 8, 044015, https://doi.org/ 10.1088/1748-9326/8/4/044015.

Shao, X., and B. Zhou, 2016: Monitoring and diagnosis of the 2015/2016 super El Niño event (in Chinese). Meteor. Mon., 42, 540-547.

Simmons, A. J., J. M. Wallace, and G. W. Branstator, 1983: Barotropic wave propagation and instability, and atmospheric 
teleconnection patterns. J. Atmos. Sci., 40, 1363-1392, https:// doi.org/10.1175/1520-0469(1983)040<1363:BWPAIA > 2.0.CO;2.

Takaya, K., and H. Nakamura, 2001: A formulation of a phaseindependent wave-activity flux for stationary and migratory quasigeostrophic eddies on a zonally varying basic flow. J. Atmos. Sci., 58, 608-627, https://doi.org/10.1175/1520-0469(2001) 058<0608:AFOAPI >2.0.CO;2.

Tang, Q., X. Zhang, X. Yang, and J. A. Francis, 2013: Cold winter extremes in northern continents linked to Arctic sea ice loss. Environ. Res. Lett., 8, 014036, https://doi.org/10.1088/17489326/8/1/014036.

Vihma, T., 2014: Effects of Arctic sea ice decline on weather and climate: A review. Surv. Geophys., 35, 1175-1214, https:// doi.org/10.1007/s10712-014-9284-0.

Wang, B., R. Wu, and X. Fu, 2000: Pacific-East Asian teleconnection: How does ENSO affect East Asian climate? J. Climate, 13, 1517-1536, https://doi.org/10.1175/1520-0442(2000)013<1517: PEATHD $>2.0 . \mathrm{CO} ; 2$.

_- J. Liu, J. Yang, T. Zhou, and Z. Wu, 2009: Distinct principal modes of early and late summer rainfall anomalies in East Asia. J. Climate, 22, 3864-3875, https://doi.org/10.1175/ 2009JCLI2850.1.

Wang, H., 2002: The instability of the East Asian summer monsoonENSO relations. Adv. Atmos. Sci., 19, 1-11, https://doi.org/ 10.1007/s00376-002-0029-5.

_ , and Y. Zhang, 2010: Model projections of East Asian summer climate under the "free Arctic" scenario. Atmos. Oceanic Sci. Lett., 3, 176-180, https://doi.org/10.1080/16742834.2010.11446865.

- , and S. He, 2015: The north China/northeastern Asia severe summer drought in 2014. J. Climate, 28, 6667-6681, https:// doi.org/10.1175/JCLI-D-15-0202.1.

- H. Chen, and J. Liu, 2015: Arctic sea ice decline intensified haze pollution in eastern China. Atmos. Ocean. Sci. Lett., 8 , 1-9, https://doi.org/10.3878/AOSL20140081.

Wu, B., R. Zhang, and B. Wang, 2009: On the association between spring Arctic sea ice concentration and Chinese summer rainfall: A further study. Adv. Atmos. Sci., 26, 666-678, https:// doi.org/10.1007/s00376-009-9009-3.
Wu, R.-G., K.-M. Hu, and Z.-D. Lin, 2018: Perspectives on the nonstationarity of the relationship between Indian and East Asian summer rainfall variations. Atmos. Oceanic Sci. Lett., 11, 104111, https://doi.org/10.1080/16742834.2018.1387758.

Xie, S.-P., K. Hu, J. Hafner, H. Tokinaga, Y. Du, G. Huang, and T. Sampe, 2009: Indian Ocean capacitor effect on Indo-western Pacific climate during the summer following El Niño. J. Climate, 22, 730-747, https://doi.org/10.1175/2008JCLI2544.1.

Xu, L., S. He, F. Li, J. Ma, and H. Wang, 2017a: Numerical simulation on the southern flood and northern drought in summer 2014 over eastern China. Theor. Appl. Climatol., 134, 1287-1299, https://doi.org/10.1007/s00704-017-2341-0.

Xu, Z., K. Fan, and H. Wang, 2017b: Role of sea surface temperature anomalies in the tropical Indo-Pacific region in the northeast Asia severe drought in summer 2014: Month-tomonth perspective. Climate Dyn., 49, 1631-1650, https:// doi.org/10.1007/s00382-016-3406-y.

Yang, J., Q. Liu, S. P. Xie, Z. Liu, and L. Wu, 2007: Impact of the Indian Ocean SST basin mode on the Asian summer monsoon. Geophys. Res. Lett., 34, L02708, https://doi.org/10.1029/ 2006GL028571.

Yuan, Y., H. Gao, W. Li, Y. Liu, L. Chen, B. Zhou, and Y. Ding, 2017: The 2016 summer floods in China and associated physical mechanisms: A comparison with 1998. J. Meteor. Res., 31, 261-277, https://doi.org/10.1007/s13351-017-6192-5.

Zeng, X., L. Bo, F. Lei, L. Xiao-Juan, and Z. Tian-Jun, 2011: East China summer rainfall during ENSO decaying years simulated by a regional climate model. Atmos. Oceanic Sci. Lett., 4, 9197, https://doi.org/10.1080/16742834.2011.11446908.

Zhai, P., and Coauthors, 2016: The strong El Niño of 2015/16 and its dominant impacts on global and China's climate. J. Meteor. Res., 30, 283-297, https://doi.org/10.1007/ s13351-016-6101-3.

Zhao, P., X. Zhang, X. Zhou, M. Ikeda, and Y. Yin, 2004: The sea ice extent anomaly in the North Pacific and its impact on the East Asian summer monsoon rainfall. J. Climate, 17, 3434-3447, https://doi.org/10.1175/1520-0442(2004)017<3434: TSIEAI $>2.0 . \mathrm{CO} ; 2$ 